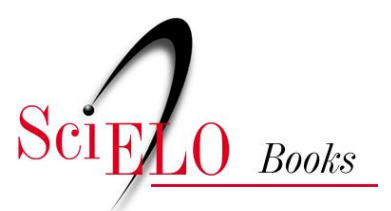

\title{
Ordem Myctophiformes
}

\author{
Ana Cristina Teixeira Bonecker \\ Claudia Akemi Pereira Namiki \\ Márcia Salustiano de Castro \\ Paula Nepomuceno Campos
}

\section{SciELO Books / SciELO Livros / SciELO Libros}

BONECKER, ACT., et al. Ordem Myctophiformes. In Catalogo dos estágios iniciais de desenvolvimento dos peixes da bacia de Campos [online]. Curitiba: Sociedade Brasileira de Zoologia, 2014, pp. 98-127. Zoologia: guias e manuais de identificação series. ISBN 978-85-98203-10-2.

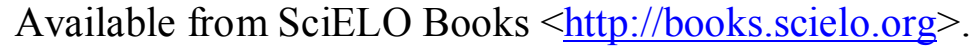

\section{(1)(9)(2)}

All the contents of this chapter, except where otherwise noted, is licensed under a Creative Commons Attribution-Non Commercial-ShareAlike 3.0 Unported.

Todo o conteúdo deste capítulo, exceto quando houver ressalva, é publicado sob a licença Creative Commons Atribuição Uso Não Comercial - Partilha nos Mesmos Termos 3.0 Não adaptada.

Todo el contenido de este capítulo, excepto donde se indique lo contrario, está bajo licencia de la licencia Creative Commons Reconocimento-NoComercial-CompartirIgual 3.0 Unported. 


\section{ORDEM MYCTOPHIFORMES}

A ordem Myctophiformes é composta por duas famílias: Neoscopelidae e Myctophidae. $O$ corpo pode variar de fino e alongado a alto com cabeça grande, possuem olhos laterais, boca geralmente grande e terminal, nadadeira adiposa. Os indivíduos em transformação apresentam fotóforos, que são importantes na identificação das espécies.

Nesse estudo a ordem Myctophiformes é representada pela família Myctophidae. 


\section{Família Myctophidae}

A família Myctophidae é marinha e ocorre em todos os oceanos incluindo o Ártico e a Antártica. Compreende aproximadamente 32 gêneros com 240 espécies. Os gêneros são separados em duas subfamílias: Myctophinae (larvas com olhos elípticos) e Lampanyctinae (larvas com olhos redondos). São peixes mesopelágicos de tamanho médio, entre 3 e $35 \mathrm{~cm}$ de comprimento, com cabeça e corpo comprimidos lateralmente. Possuem uma única nadadeira dorsal seguida de nadadeira adiposa. A morfologia e o padrão de pigmentação do corpo são características muito importantes para a identificação das larvas. O número e o padrão de distribuição dos fotóforos são únicos para cada espécie, sendo fundamental para a identificação de indivíduos que já sofreram transformação. $\mathrm{Na}$ figura 56 está representado um exemplar hipotético da família Myctophidae com a denominação e posição dos fotóforos.

No Brasil já foram identificadas 80 espécies nas fases de larva e adulto. Nesse estudo são contempladas as espécies Benthosema suborbitale, Bolinichthys distofax, Centrobranchus nigroocelatus, Ceratoscopelus warmingii, Diaphus anderseni, Diaphus dumerilii, Diaphus mollis, Diaphus splendidus, Hygophum hygomii, Hygophum reinhardtii, Hygophum taaningi, Lampadena sp., Lampanyctus alatus, Lepidophanes gaussi, Lepidophanes guentheri, Lobianchia gemellarii, Myctophum affine, Myctophum nitidulum, Myctophum obtusirostre, Notolychnus valdiviae, Notoscopelus caudispinosus e Symbolophorus rufinus.

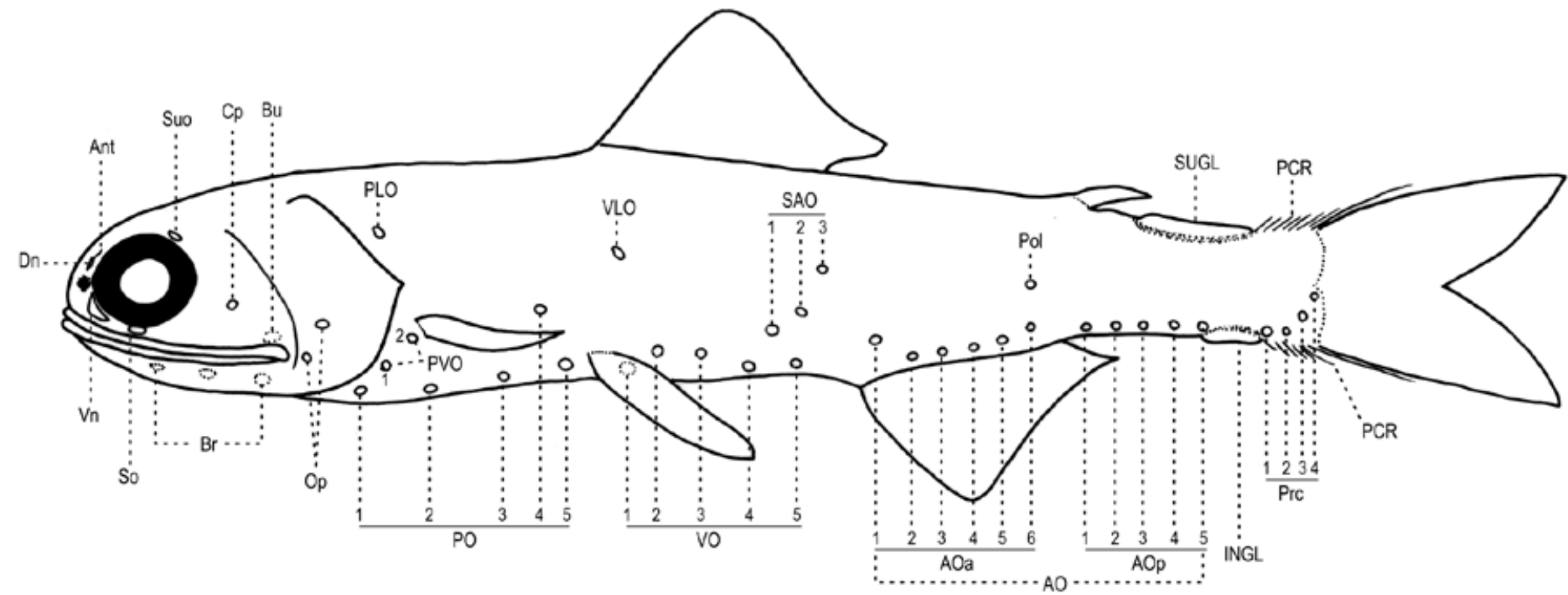

Figura 56: Padrão geral de fotóforos e terminologia utilizada para Myctophidae (modificado de Moser \& Ahlstrom, 1996). $A n t=$ fotóforo anterorbital; $A O=$ série anal; $A O a=$ fotóforos anais anteriores; $A O p=$ fotóforos anais posteriores; $B R=$ série branquiostégia; $\mathrm{Bu}$ = fotóforo bucal; $\mathrm{Cp}=$ fotóforo da face; $\mathrm{Dn}$ = fotóforo dorso-nasal; $\mathrm{INGL}=$ glândula luminosa infracaudal; $\mathrm{Op}$ = fotóforos operculares; $\mathrm{PLO}=$ fotóforo suprapeitoral; $\mathrm{PO}=$ série toráxica ou peitoral; Pol = fotóforo posterolateral; Prc = série pré-caudal; PVO = fotóforos subpeitorais; SAO = série supra-anal; So = fotóforo suborbital; SUGL = glândula luminosa supracaudal; Suo = fotóforo supraorbital; VLO = fotóforo supravental; Vn = fotóforo ventronasal; VO = série ventral. 


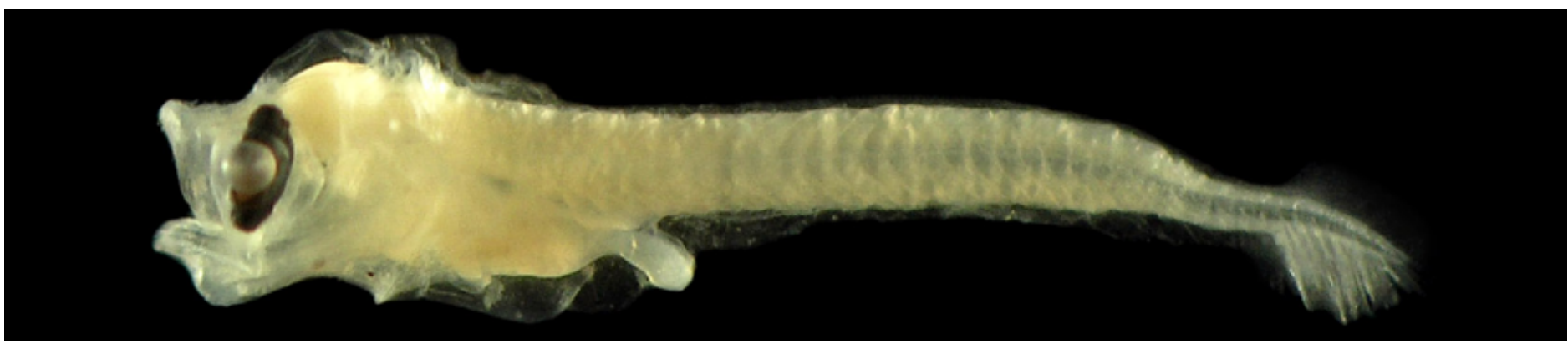

Figura 56 - A: Benthosema suborbitale. DZUFRJ 33548; Pré-flexão; CP 4,1 mm.

\section{Benthosema suborbitale (Gilbert, 1913)}

Possui olhos elípticos e intestino curto. Nos estágios de pré-flexão e flexão, a base da nadadeira anal é distante do ânus, o que separa facilmente essa espécie de algumas espécies de Hygophum que apresentam o corpo semelhante à $B$. suborbitale. Na pré-flexão possuem apenas um pigmento na região anterior à sínfise do cleitro. Na flexão surge um fotóforo na maxila inferior e manchas de melanóforos internos na região anterior a base da nadadeira peitoral. As larvas que já sofreram transformação apresentam um fotóforo suborbital; VO2 muito elevado ficando sobre ou um pouco atrás do VO1; SAO angular; 2 Prc, o segundo situado na linha lateral; $6 \mathrm{AOa}$ e 5 (4 a 6) AOp. O número de miômeros varia entre 33 e 35.

Tamanho: pré-flexão 2,7-5,0 mm; flexão 5,2-7,3 mm; pós-flexão 9,5-10,9 mm; transformação 11,5 mm.

Habitat: espécie marinha, epi-mesopelágica, ocorre em águas tropicais e subtropicais entre 375 e 750 m de profundidade durante o dia. A noite ocorre desde a superfície até $125 \mathrm{~m}$ de profundidade.

Nome vulgar: Peixe-lanterna.

\section{Georreferenciamento}

\begin{tabular}{|c|c|c|c|c|c|c|c|c|}
\hline DZUFR & Latitude (S) & Longitude (W) & Data & $\begin{array}{c}\text { Tipo de } \\
\text { arrasto }\end{array}$ & $\begin{array}{c}\text { Profundidade } \\
\text { de coleta }\end{array}$ & Rede & $\begin{array}{c}\text { Malha } \\
\text { ( } \boldsymbol{\mu m})\end{array}$ & $\begin{array}{c}\text { No. de } \\
\text { inds. }\end{array}$ \\
\hline 5518 & $22^{\circ} 31^{\prime} 58,9^{\prime \prime}$ & $040^{\circ} 02^{\prime} 53,4^{\prime \prime}$ & $07 / 11 / 2001$ & oblíquo & $1.000 \mathrm{~m}$ & cilíndrico-cônica & 500 & 1 \\
\hline 5520 & $22^{\circ} 31^{\prime} 58,9^{\prime \prime}$ & $040^{\circ} 02^{\prime} 53,4^{\prime \prime}$ & $07 / 11 / 2001$ & oblíquo & $1.000 \mathrm{~m}$ & cilíndrico-cônica & 500 & 1 \\
\hline 7390 & $21^{\circ} 54^{\prime} 36,5^{\prime \prime}$ & $039^{\circ} 45^{\prime} 20,0^{\prime \prime}$ & $10 / 10 / 2001$ & oblíquo & $1.000 \mathrm{~m}$ & cilíndrico-cônica & 500 & 1 \\
\hline 7564 & $21^{\circ} 58^{\prime} 31,0^{\prime \prime}$ & $039^{\circ} 50^{\prime} 29,7^{\prime \prime}$ & $10 / 10 / 2001$ & oblíquo & $1.000 \mathrm{~m}$ & cilíndrico-cônica & 500 & 4 \\
\hline 7568 & $21^{\circ} 53^{\prime} 10,4^{\prime \prime}$ & $039^{\circ} 45^{\prime} 49,9^{\prime \prime}$ & $10 / 10 / 2001$ & oblíquo & $1.000 \mathrm{~m}$ & cilíndrico-cônica & 500 & 2 \\
\hline 22009 & $21^{\circ} 58^{\prime} 31,0^{\prime \prime}$ & $039^{\circ} 50^{\prime} 29,7^{\prime \prime}$ & $10 / 10 / 2001$ & oblíquo & $1.000 \mathrm{~m}$ & cilíndrico-cônica & 500 & 7 \\
\hline 22052 & $22^{\circ} 07^{\prime} 29,0^{\prime \prime}$ & $039^{\circ} 06^{\prime} 23,5^{\prime \prime}$ & $10 / 05 / 2002$ & oblíquo & $1.000 \mathrm{~m}$ & cilíndrico-cônica & 500 & 1 \\
\hline 22786 & $22^{\circ} 32^{\prime} 49,0^{\prime \prime}$ & $040^{\circ} 04^{\prime} 29^{\prime \prime}$ & $07 / 11 / 2001$ & oblíquo & $1.000 \mathrm{~m}$ & cilíndrico-cônica & 500 & 1 \\
\hline
\end{tabular}

Referências: Nafpakititis et al., 1977; Moser \& Ahlstrom, 1996; Castro \& Bonecker, 2006c; Moser \& Watson, 2006; Fahay, 2007.

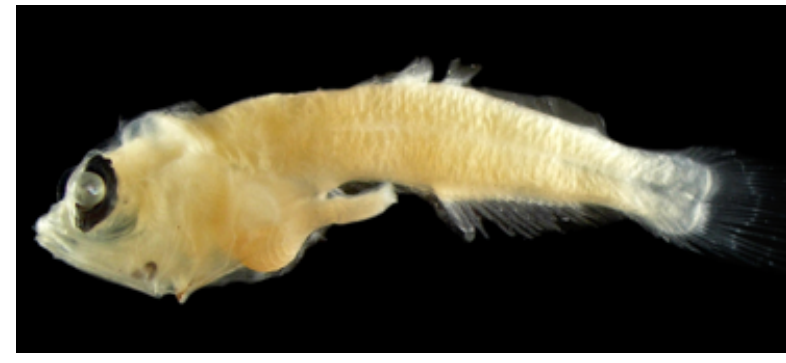

Figura 56 - B: DZUFRJ 33547; Flexão; CP 6,0 mm.

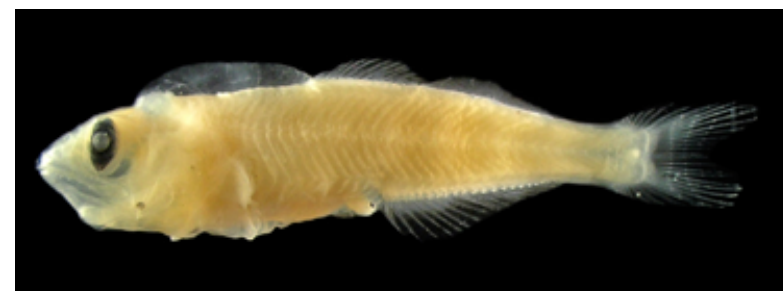

Figura 56 - C: DZUFRJ 33546; Pós-flexão; CP 10,9 mm.

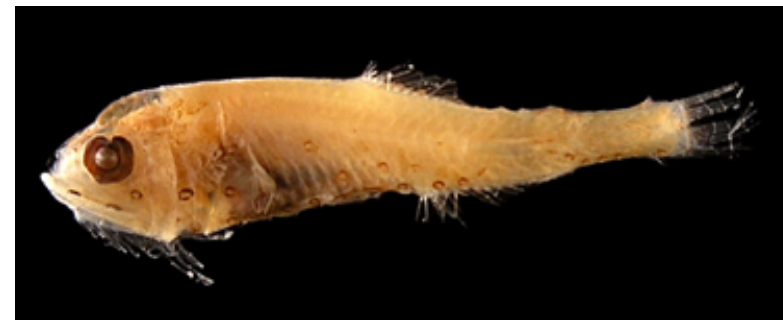

Figura 56 - D: DZUFRJ 22009; Transformação; CP $11,5 \mathrm{~mm}$. 


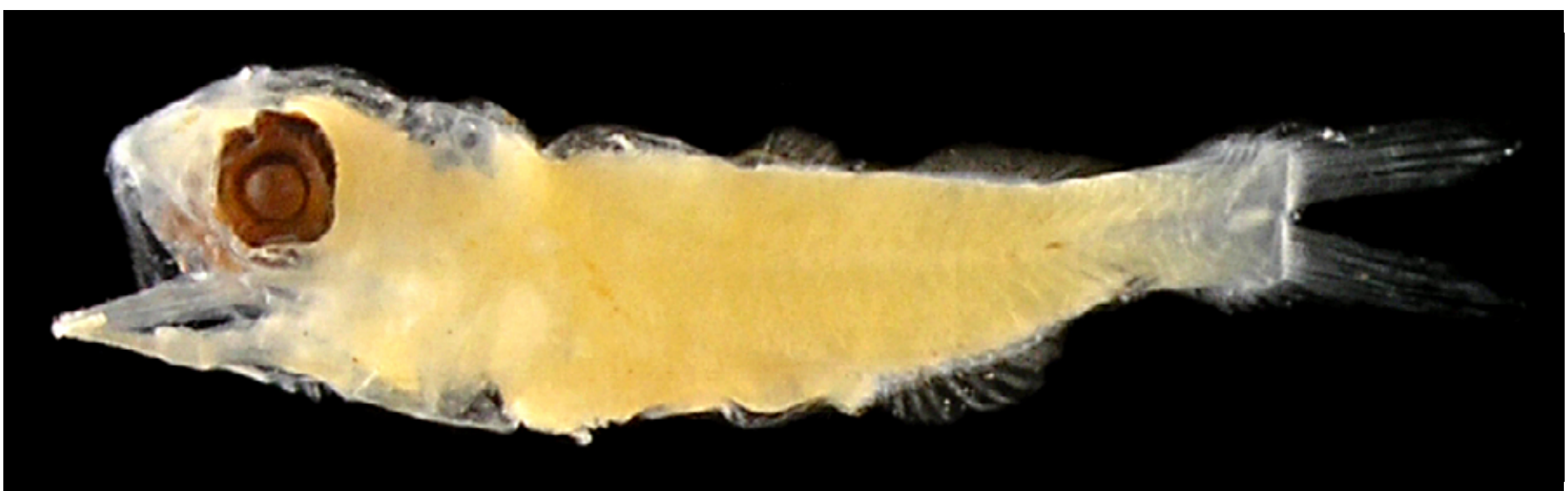

Figura 57 - A: Bolinichthys distofax. DZUFRJ 23790; Flexão; CP 5,1 mm.

\section{Bolinichthys distofax Johnson, 1975}

As larvas em estágio de flexão possuem uma série de pigmentos na região da linha lateral na cauda que é única dessa espécie. Os indivíduos que já sofreram transformação possuem o último AOa um pouco elevado e não apresentam tecido luminoso na base da nadadeira pélvica. Possui 6 (5) AOa e 4 (5) AOp; 1 Pol; 3 Prc e um total de 34 vértebras.

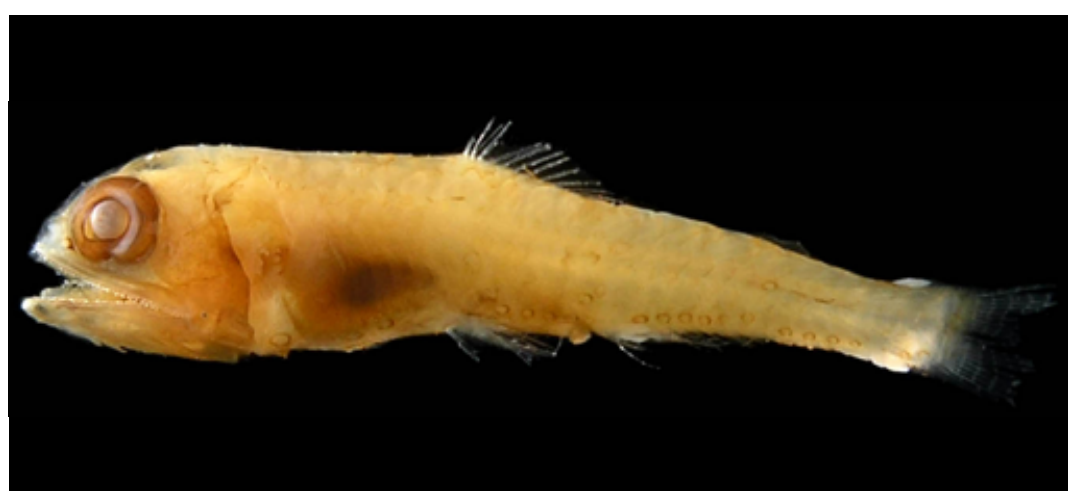

Figura 57 - B: DZUFRJ 22155; Transformação; CP 17,3 mm.

Tamanho: flexão 5,1-5,5 mm; transformação 15,5-17,3 mm.

Habitat: espécie marinha, ocorre em águas tropicais e subtropicais entre 100 e $690 \mathrm{~m}$ de profundidade.

Nome vulgar: Peixe-lanterna.

\section{Georreferenciamento}

\begin{tabular}{|c|c|c|c|c|c|c|c|c|}
\hline DZUFRJ & Latitude (S) & Longitude (W) & Data & $\begin{array}{l}\text { Tipo de } \\
\text { arrasto }\end{array}$ & $\begin{array}{l}\text { Profundidade } \\
\text { de coleta }\end{array}$ & Rede & $\begin{array}{c}\text { Malha } \\
(\mu \mathrm{m})\end{array}$ & $\begin{array}{l}N^{\circ} \text {. de } \\
\text { inds. }\end{array}$ \\
\hline 22069 & $21^{\circ} 57,51^{\prime}$ & $039^{\circ} 49,57^{\prime}$ & $19 / 06 / 2003$ & vertical & $500-1.150 \mathrm{~m}$ & cilíndrico-cônica & 500 & 1 \\
\hline 22155 & $21^{\circ} 57^{\prime} 10,5^{\prime \prime}$ & $039^{\circ} 43^{\prime} 33,3^{\prime \prime}$ & 09/10/2001 & oblíquo & $1.000 \mathrm{~m}$ & cilíndrico-cônica & 500 & 1 \\
\hline 23790 & $22^{\circ} 03^{\prime} 03,3^{\prime \prime}$ & $039^{\circ} 50^{\prime} 39,0^{\prime \prime}$ & $10 / 05 / 2002$ & oblíquo & até a termoclina & bongô & 330 & 3 \\
\hline
\end{tabular}

Referências: Nafpakititis et al., 1977; Moser \& Ahlstrom, 1996; Moser \& Watson, 2006; Santos \& Figueiredo, 2008. 


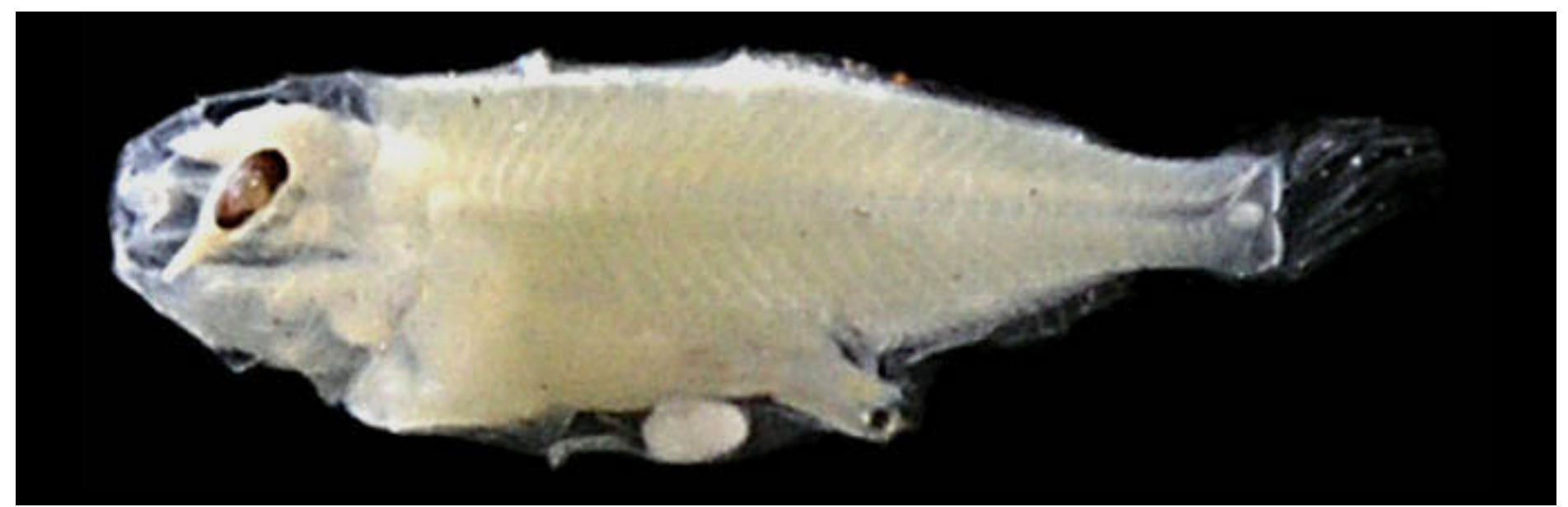

Figura 58: Centrobranchus nigroocelatus. DZUFRJ 22173; Pós-flexão; CP 7,4mm.

\section{Centrobranchus nigroocelatus (Günther, 1873)}

As larvas em pré-flexão são moderadamente alongadas, mas o corpo torna-se alto e muito comprimido ao longo do desenvolvimento. As membranas embrionárias são grandes e permanecem até a transformação. A cabeça é grande, e os olhos são estreitos e elípticos, com tecido coroide muito alongado e sem pigmento. As larvas em pós-flexão possuem pigmento na margem posterior da órbita. O número de miômeros varia entre 35 e 40.

Tamanho: pós-flexão 7,4 mm.

Habitat: espécie marinha, mesopelágica, ocorre em águas tropicais e subtropicais entre 375 e $650 \mathrm{~m}$ de profundidade durante o dia. A noite ocorre próximo à superfície.

Nome vulgar: Peixe-lanterna.

\section{Georreferenciamento}

\begin{tabular}{|c|c|c|c|c|c|c|c|c|}
\hline DZUFRJ & Latitude (S) & Longitude (W) & Data & $\begin{array}{c}\text { Tipo de } \\
\text { arrasto }\end{array}$ & $\begin{array}{c}\text { Profundidade } \\
\text { de coleta }\end{array}$ & Rede & $\begin{array}{c}\text { Malha } \\
(\boldsymbol{\mu} \text { m) }\end{array}$ & $\begin{array}{c}\text { No. de } \\
\text { inds. }\end{array}$ \\
\hline 22173 & $22^{\circ} 37^{\prime} 21,9^{\prime \prime}$ & $040^{\circ} 02^{\prime} 425^{\prime \prime}$ & $08 / 12 / 2002$ & vertical & $200-500 \mathrm{~m}$ & cilíndrico-cônica & 200 & 1 \\
\hline
\end{tabular}

Referências: Moser \& Ahlstrom, 1996; Castro \& Bonecker, 2006c; Moser \& Watson, 2006; Fahay, 2007. 


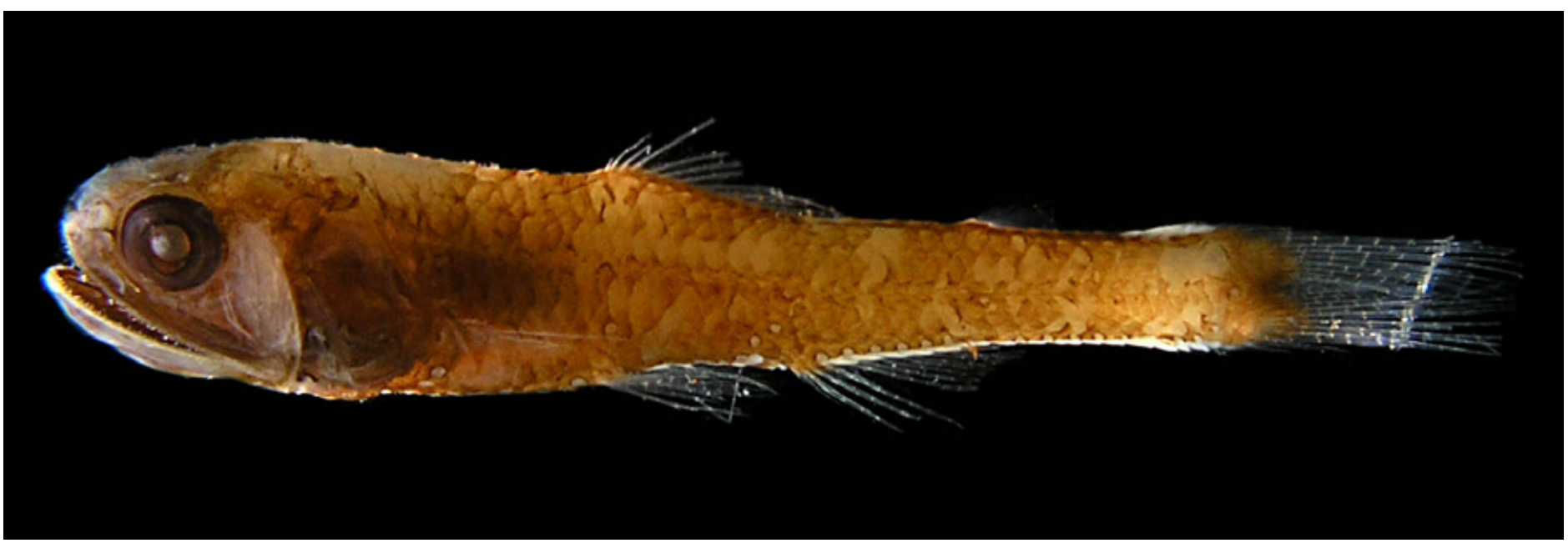

Figura 59: Ceratoscopelus warmingii. DZUFRJ 22156; Juvenil; CP 23,0 mm.

\section{Ceratoscopelus warmingii (Lütken, 1892)}

Os juvenis possuem 6 (5-7) AOa e 5 (4-6) AOp; 2 Pol; 4 Prc. Os indivíduos dessa espécie podem ser separados também pelo número de rastros branquiais 4(3) + $1+9-10(8)=14-15$ (13); pela ausência de espinhos supraorbitais e pela presença de tecido luminoso ao longo da margem ventral do corpo. O número de miômeros varia entre 35 e 36.

Tamanho: juvenil 17,0-23,0 mm.

Habitat: espécie marinha, epi-mesopelágica, ocorre em águas tropicais e subtropicais entre 425 e $1.000 \mathrm{~m}$ de profundidade durante o dia. A noite ocorre desde próximo à superfície até $125 \mathrm{~m}$ de profundidade.

Nome vulgar: Peixe-lanterna.

\section{Georreferenciamento}

\begin{tabular}{|c|c|c|c|c|c|c|c|c|}
\hline DZUFRJ & Latitude (S) & Longitude (W) & Data & $\begin{array}{l}\text { Tipo de } \\
\text { arrasto }\end{array}$ & $\begin{array}{l}\text { Profundidade } \\
\text { de coleta }\end{array}$ & Rede & $\begin{array}{c}\text { Malha } \\
(\mu \mathrm{m})\end{array}$ & $\begin{array}{l}N^{\circ} \text {. de } \\
\text { inds. }\end{array}$ \\
\hline 21982 & $21^{\circ} 58^{\prime} 31,0^{\prime \prime}$ & $039^{\circ} 50^{\prime} 29,7 "$ & $11 / 10 / 2001$ & oblíquo & $1.000 \mathrm{~m}$ & cilíndrico-cônica & 500 & 2 \\
\hline 22020 & & $0^{\prime \prime}$ & $10 / 10$ & oblíquo & $1.000 \mathrm{~m}$ & cilíndrico-cônica & 500 & 1 \\
\hline 22084 & $22^{\circ} 31^{\prime} 40,9^{\prime \prime}$ & $040^{\circ} 02^{\prime} 39,6^{\prime \prime}$ & $07 / 11 / 2001$ & oblíq & 1.0 & cilíndrico-cônica & 500 & 1 \\
\hline 22086 & $22^{\circ} 31^{\prime} 40,9^{\prime \prime}$ & $040^{\circ} 02^{\prime} 39,6^{\prime \prime}$ & $07 / 11 / 2001$ & oblíquo & $1.000 \mathrm{~m}$ & cilíndrico-cônica & 500 & 1 \\
\hline 22156 & $21^{\circ} 57^{\prime} 10,5^{\prime \prime}$ & $039^{\circ} 43^{\prime} 33,3^{\prime \prime}$ & 09/10/2001 & oblíquo & $1.000 \mathrm{~m}$ & cilíndrico-cônica & 500 & 1 \\
\hline 22711 & $21^{\circ} 54^{\prime} 36,5^{\prime \prime}$ & $039^{\circ} 45^{\prime} 20,0^{\prime \prime}$ & $10 / 10 / 2001$ & oblíquo & $1.000 \mathrm{~m}$ & cilíndrico-cônica & 500 & 2 \\
\hline
\end{tabular}

Referências: Nafpakititis et al., 1977; Castro \& Bonecker, 2006c; Santos \& Figueiredo, 2008. 


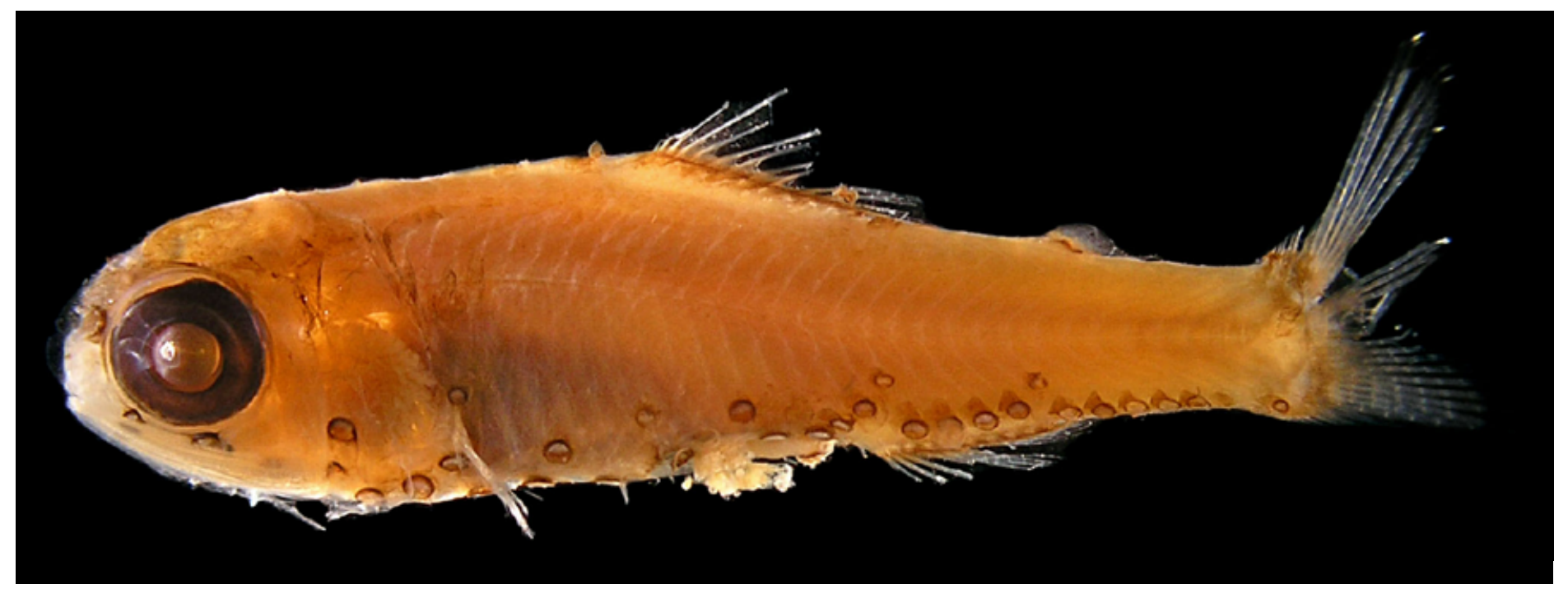

Figura 60: Diaphus anderseni. DZUFRJ 22794; Juvenil; CP 23,5 mm.

\section{Diaphus anderseni Tåning, 1932}

Os juvenis apresentam Dn, Vn e So redondos e grandes. Os fotóforos são maiores que a maioria das espécies de Diaphus. SAO está em linha reta ou um pouco angulado; 4 Prc formando um arco; 1 Pol; 4 Aoa e 4 a 5 AOp.

Tamanho: juvenil 11,7-23,5 mm.

Habitat: espécie marinha, mesopelágica, ocorrendo entre 100 e $500 \mathrm{~m}$ de profundidade.

Nome vulgar: Peixe-lanterna.

\section{Georreferenciamento}

\begin{tabular}{|c|c|c|c|c|c|c|c|c|}
\hline DZUFRJ & Latitude (S) & Longitude (W) & Data & $\begin{array}{c}\text { Tipo de } \\
\text { arrasto }\end{array}$ & $\begin{array}{c}\text { Profundidade } \\
\text { de coleta }\end{array}$ & Rede & $\begin{array}{c}\text { Malha } \\
\text { ( } \boldsymbol{\mu m})\end{array}$ & $\begin{array}{c}\mathbf{N}^{\circ} \text {. de } \\
\text { inds. }\end{array}$ \\
\hline 22794 & $21^{\circ} 58^{\prime} 31,0^{\prime \prime}$ & $039^{\circ} 50^{\prime} 29,7^{\prime \prime}$ & $11 / 10 / 2001$ & oblíquo & $1.000 \mathrm{~m}$ & cilíndrico-cônica & 500 & 1 \\
\hline 22797 & $22^{\circ} 08^{\prime} 17,5^{\prime \prime}$ & $039^{\circ} 46^{\prime} 28,5^{\prime \prime}$ & $11 / 05 / 2002$ & oblíquo & $1.000 \mathrm{~m}$ & cilíndrico-cônica & 500 & 1 \\
\hline 22800 & $22^{\circ} 02^{\prime} 30,0^{\prime \prime}$ & $09^{\circ} 49^{\prime} 41,2^{\prime \prime}$ & $12 / 05 / 2002$ & oblíquo & $1.000 \mathrm{~m}$ & cilíndrico-cônica & 500 & 1 \\
\hline
\end{tabular}

Referências: Nafpakititis et al., 1977; Castro \& Bonecker, 2006c; Santos \& Figueiredo, 2008. 


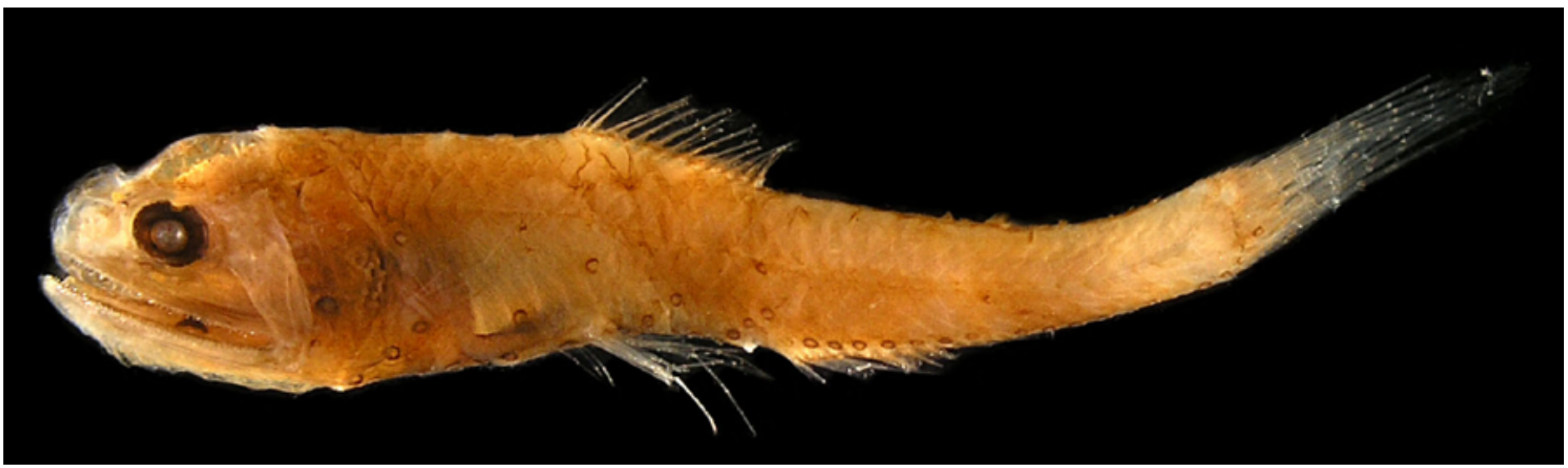

Figura 61 - A: Diaphus dumerilii. DZUFRJ 21983; Transformação; CP 16,0 mm.

\section{Diaphus dumerilii (Bleeker, 1856)}

Os indivíduos em transformação podem ser facilmente separados dos demais Diaphus por apresentarem os fotóforos $\mathrm{AOa}$ em linha reta; 7 (6 a 8) AOa e 5 (5 a 6) AOp; SAO angular; 4 Prc formando um arco; 1 Pol; Vn pequeno e situado na margem ventral anterior da pupila.

Tamanho: transformação 16,0-17,0 mm; juvenil $26,5 \mathrm{~mm}$; adulto $65,0 \mathrm{~mm}$.

Habitat: espécie marinha, mesopelágica, ocorrendo até $805 \mathrm{~m}$ de profundidade.

Nome vulgar: Peixe-lanterna.

\section{Georreferenciamento}

\begin{tabular}{|c|c|c|c|c|c|c|c|c|}
\hline DZUFRJ & Latitude & Longitude & Data & $\begin{array}{l}\text { Tipo de } \\
\text { arrasto }\end{array}$ & $\begin{array}{c}\text { Profundidade } \\
\text { de coleta }\end{array}$ & Rede & $\begin{array}{l}\text { Malha } \\
(\mu \mathrm{m})\end{array}$ & $\begin{array}{l}\text { No. de } \\
\text { inds. }\end{array}$ \\
\hline 21983 & $21^{\circ} 58 ' 31,0^{\prime \prime}$ & $039^{\circ} 50 ' 29,7^{\prime \prime}$ & $10 / 10 / 2001$ & oblíquo & $1.000 \mathrm{~m}$ & cilíndrico-cônica & 500 & 1 \\
\hline 21995 & $22^{\circ} 07^{\prime} 58,8^{\prime \prime}$ & $039^{\circ} 49^{\prime} 08,9^{\prime \prime}$ & $02 / 12 / 2002$ & vertical & $200-1.100 m$ & cilíndrico-cônica & 200 & 6 \\
\hline 22141 & $21^{\circ} 54 ' 36,5^{\prime \prime}$ & $039^{\circ} 45^{\prime} 20,0^{\prime \prime}$ & $10 / 10 / 2001$ & oblíquo & $1.000 \mathrm{~m}$ & cilíndrico-cônica & 500 & 1 \\
\hline 22149 & $21^{\circ} 53^{\prime} 10,4^{\prime \prime}$ & $039^{\circ} 45^{\prime} 49,9^{\prime \prime}$ & $10 / 10 / 2001$ & oblíquo & $1.000 \mathrm{~m}$ & cilíndrico-cônica & 500 & 1 \\
\hline
\end{tabular}

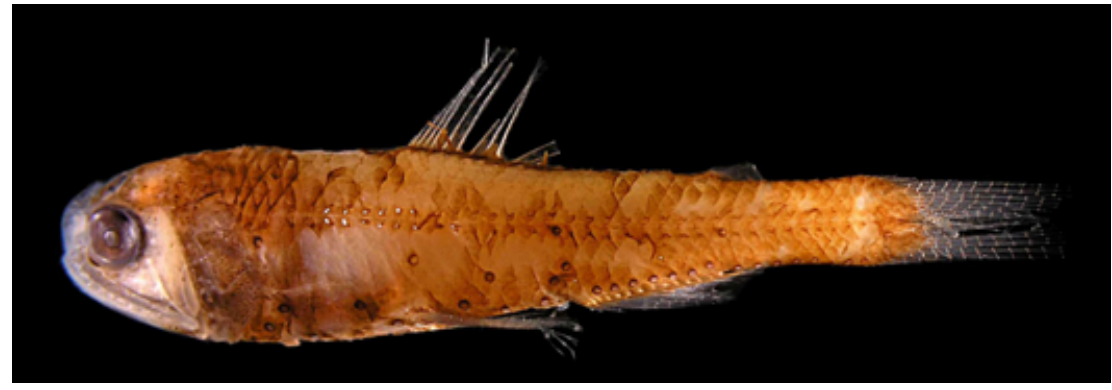

Figura 61 - B: DZUFRJ 22149; Juvenil; CP 26,5 mm.

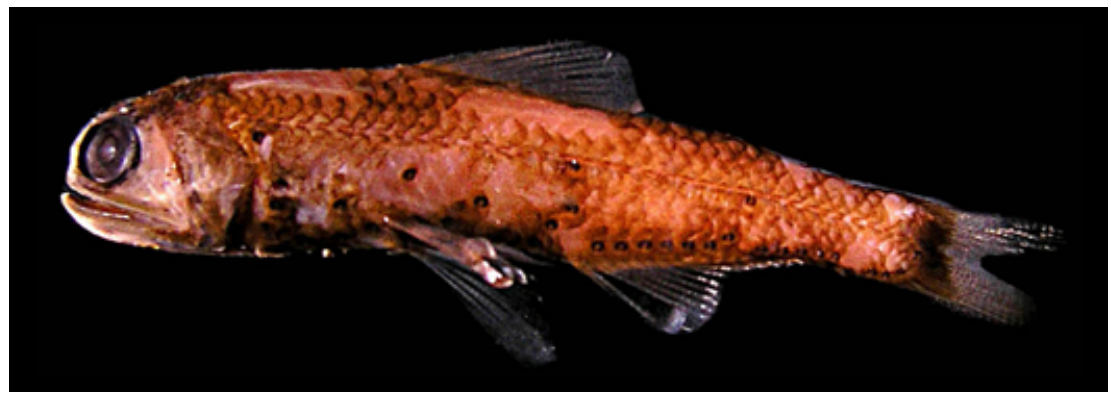

Figura 61 - C: DZUFRJ 22141; Adulto; CP 65,0 mm.

Referências: Nafpakititis et al., 1977; Castro \& Bonecker, 2006c; Santos \& Figueiredo, 2008. 


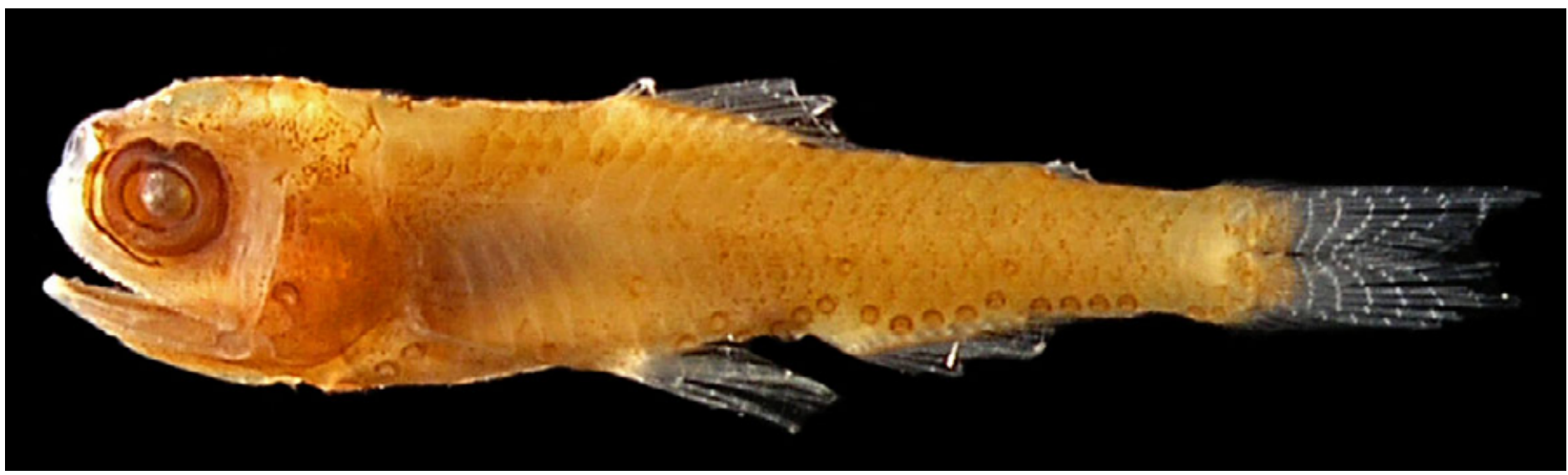

Figura 62: Diaphus mollis. DZUFRJ 22795; Transformação; CP 12,5 mm.

\section{Diaphus mollis Tåning, 1928}

Os indivíduos em transformação podem ser separados dos demais Diaphus por apresentarem o Vn alongado; SAO em ângulo obtuso e SAO1 localizado acima e atrás do VO5; 5 (4 a 6) AOa e 4 (3 a 5) AOp; AOa1 elevado e no nível do SAO2; 4 Prc formando um arco; 1 Pol. O número de miômeros varia entre 33 e 34 .

Tamanho: transformação 12,3-12,5 mm.

Habitat: espécie marinha, mesopelágica, ocorrendo entre 300 e 600 m de profundidade. Durante a noite migra para próximo da superfície.

Nome vulgar: Peixe-lanterna.

\section{Georreferenciamento}

\begin{tabular}{|c|c|c|c|c|c|c|c|c|}
\hline DZUFR & Latitude (S) & Longitude (W) & Data & $\begin{array}{c}\text { Tipo de } \\
\text { arrasto }\end{array}$ & $\begin{array}{c}\text { Profundidade } \\
\text { de coleta }\end{array}$ & Rede & $\begin{array}{c}\text { Malha } \\
\text { ( } \boldsymbol{\mu m})\end{array}$ & $\begin{array}{c}\mathbf{N}^{\circ} \text {. de } \\
\text { inds. }\end{array}$ \\
\hline 22792 & $21^{\circ} 53^{\prime} 10,4^{\prime \prime}$ & $039^{\circ} 45^{\prime} 49,9^{\prime \prime}$ & $10 / 10 / 2001$ & oblíquo & $1.000 \mathrm{~m}$ & cilíndrico-cônica & 500 & 1 \\
\hline 22795 & $22^{\circ} 06^{\prime} 52,3^{\prime \prime}$ & $039^{\circ} 48^{\prime} 46,2^{\prime \prime}$ & $11 / 05 / 2002$ & oblíquo & $1.000 \mathrm{~m}$ & cilíndrico-cônica & 500 & 1 \\
\hline
\end{tabular}

Referências: Nafpakititis et al., 1977; Fahay, 2007; Santos \& Figueiredo, 2008. 


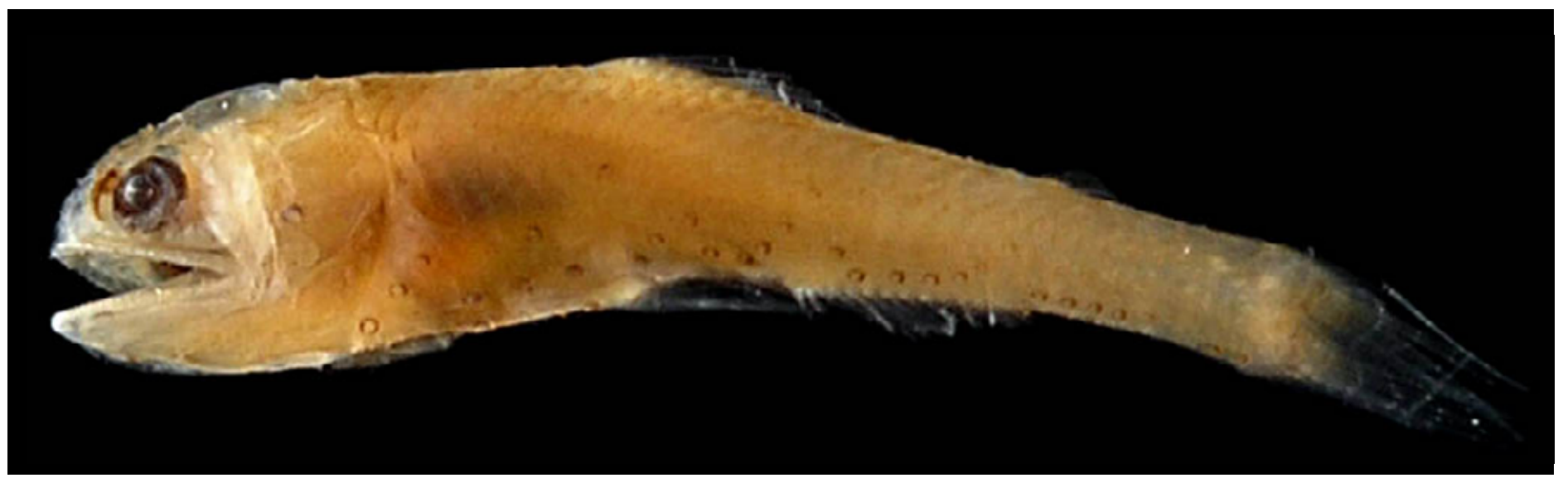

Figura 63: Diaphus splendidus. DZUFRJ 22162; Transformação; CP 12,3mm.

\section{Diaphus splendidus (Brauer, 1904)}

Os indivíduos em transformação não apresentam SO; possuem SAO em linha reta ou um pouco angulado; VLO próximo a linha lateral; 4 Prc formando um arco; 1 Pol, próximo a linha lateral; 6 (7) AOa e 6 (5) AOp. A espécie possui uma escama luminosa triangular grande no PLO e um espinho supraorbital.

Tamanho: transformação 12,3-17,0 mm.

Habitat: espécie marinha, mesopelágica, ocorrendo entre 40 e 3.872 m de profundidade.

Nome vulgar: Peixe-lanterna

\section{Georreferenciamento}

\begin{tabular}{|c|c|c|c|c|c|c|c|c|}
\hline DZUFR & Latitude (S) & Longitude (W) & Data & $\begin{array}{c}\text { Tipo de } \\
\text { arrasto }\end{array}$ & $\begin{array}{c}\text { Profundidade } \\
\text { de coleta }\end{array}$ & Rede & $\begin{array}{c}\text { Malha } \\
\text { ( } \boldsymbol{\mu m})\end{array}$ & $\begin{array}{c}\mathbf{N}^{\circ} \text {. de } \\
\text { inds. }\end{array}$ \\
\hline 22162 & $22^{\circ} 07^{\prime} 29,0^{\prime \prime}$ & $039^{\circ} 06^{\prime} 23,5^{\prime \prime}$ & $10 / 05 / 2002$ & oblíquo & $1.000 \mathrm{~m}$ & cilíndrico-cônica & 500 & 1 \\
\hline 22799 & $22^{\circ} 08^{\prime} 17,5^{\prime \prime}$ & $039^{\circ} 46^{\prime} 28,5^{\prime \prime}$ & $11 / 05 / 2002$ & oblíquo & $1.000 \mathrm{~m}$ & cilíndrico-cônica & 500 & 1 \\
\hline
\end{tabular}

Referências: Nafpakititis et al., 1977; Castro \& Bonecker, 2006c; Santos \& Figueiredo, 2008. 


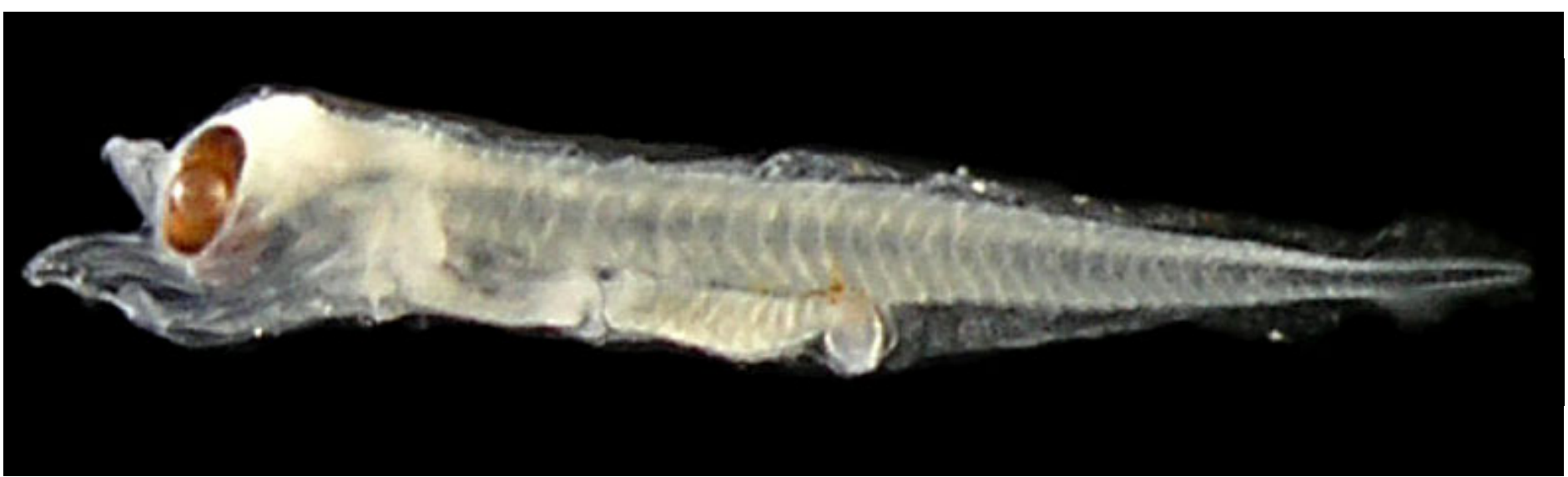

Figura 64: Hygophum hygomii. DZUFRJ 7586; Pré-flexão; CP 3,3 mm.

\section{Hygophum hygomii (Lütken, 1892)}

Possui olhos moderadamente elípticos com massa de tecido coroide amarronzado na margem ventral. A nadadeira anal começa próximo ao ânus. Apresenta um fotóforo no istmo e pigmentos no cleitro e no final do intestino, próximo ao ânus. Em alguns exemplares é possível ver melanóforos na margem da membrana dorsal. O número de miômeros varia entre 36 e 38.

Tamanho: pré-flexão 3,3 mm.

Habitat: espécie marinha, epi-mesopelágica, ocorre em águas temperadas e subtropicais entre 425 e $750 \mathrm{~m}$ de profundidade durante o dia. A noite ocorre desde próximo à superfície até $125 \mathrm{~m}$ de profundidade.

Nome vulgar: Peixe-lanterna.

\section{Georreferenciamento}

\begin{tabular}{|c|c|c|c|c|c|c|c|c|}
\hline DZUFR & Latitude (S) & Longitude (W) & Data & $\begin{array}{c}\text { Tipo de } \\
\text { arrasto }\end{array}$ & $\begin{array}{c}\text { Profundidade } \\
\text { de coleta }\end{array}$ & Rede & $\begin{array}{c}\text { Malha } \\
\text { ( } \boldsymbol{\mu m} \text { ) }\end{array}$ & $\begin{array}{c}\mathbf{N}^{\circ} \text {. de } \\
\text { inds. }\end{array}$ \\
\hline 7586 & $22^{\circ} 02,2^{\prime}$ & $039^{\circ} 43,49^{\prime}$ & $18 / 06 / 2003$ & vertical & $90 \mathrm{~m}$ & cilíndrico-cônica & 500 & 1 \\
\hline 23980 & $21^{\circ} 58^{\prime} 31,0^{\prime \prime}$ & $039^{\circ} 50^{\prime} 29,7^{\prime \prime}$ & $10 / 10 / 2001$ & oblíquo & $1.000 \mathrm{~m}$ & cilíndrico-cônica & 500 & 1 \\
\hline
\end{tabular}

Referências: Moser \& Ahlstrom, 1996; Castro \& Bonecker, 2006c; Moser \& Watson, 2006; Fahay, 2007. 


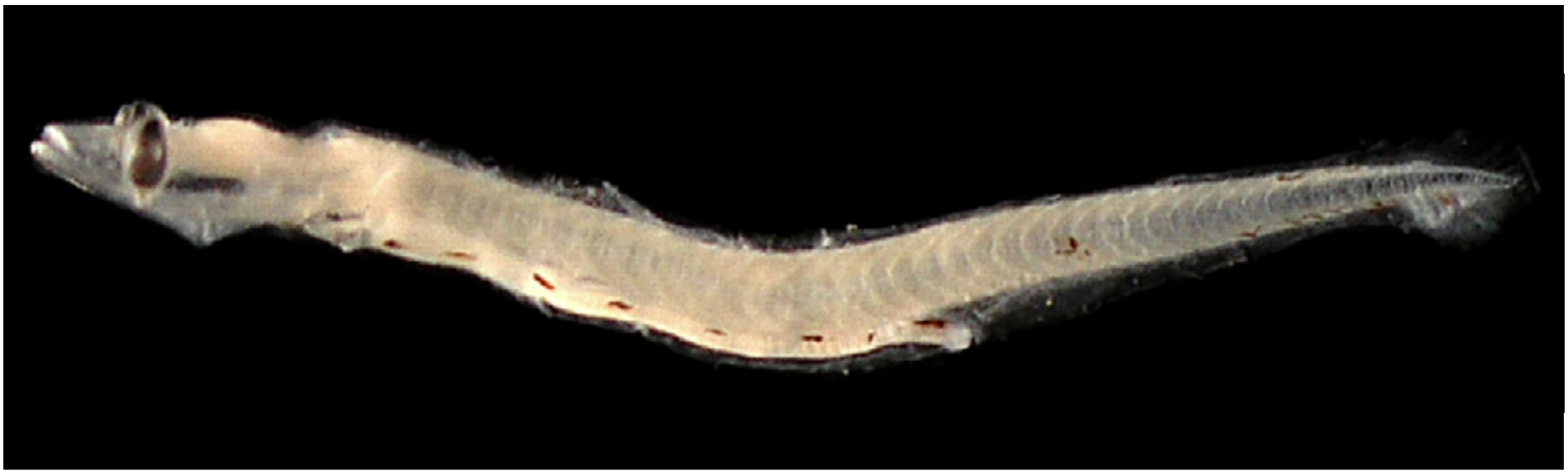

Figura 65 - A: Hygophum reinhardtii. DZUFRJ 14694; Pré-flexão; CP 6,8 mm.

\section{Hygophum reinhardtii (Lütken, 1892)}

Nos estágios de pré-flexão, flexão e pós-flexão essa espécie possui olhos muito elípticos e um pouco pedunculados, com tecido coroide cônico ventral. Tem corpo alongado e intestino longo, que alcança a metade do corpo. Durante o desenvolvimento o padrão de pigmentação varia. Na pré-flexão possui pigmentos logo após o cleitro, um par dorsal no final do intestino, dois pares na região lateral do intestino, entre outros. Durante a flexão há um pigmento no opérculo, até oito na região lateral do intestino, uma série de sete a 12 na região pós-anal começando na base da nadadeira anal. Na pós-flexão possui cinco a dez no miossepto na região pós-anal, até oito pares laterais no intestino e até 15 na base da nadadeira anal. 0 número de miômeros varia entre 38 e 40. Na transformação os fotóforos Br1, PO1, PO5, e VO4 são os primeiros que aparecem. Os indivíduos em transformação, juvenis e adultos possuem SAO1 um pouco atrás do VO2 e abaixo de uma linha reta conectando SAO2 com VLO. Possui SAO3 na direção da origem da nadadeira anal e em contato com a linha lateral; 2 Pol, o segundo à frente da base da nadadeira adiposa e em contato com a linha lateral; 2 Prc, o segundo situado na linha lateral; 7 (6 a 8) AOa e 7 (6 a 9) AOp. Nesses estágios o olho fica arredondado e há uma regressão do tecido coroide.

Tamanho: pré-flexão 3,8-8,4 mm; flexão 9,1-10,2 mm; pós-flexão 11,2$14,8 \mathrm{~mm}$; transformação 15,6-15,7 $\mathrm{mm}$; juvenil 16,0 mm; adulto 36,0 $\mathrm{mm}$.

Habitat: espécie marinha, epi-mesopelágica, ocorre em águas tropicais e subtropicais entre 475 e 850 $m$ de profundidade durante o dia. A noite ocorre desde próximo à superfície até $175 \mathrm{~m}$ de profundidade.

Nome vulgar: Peixe-lanterna.

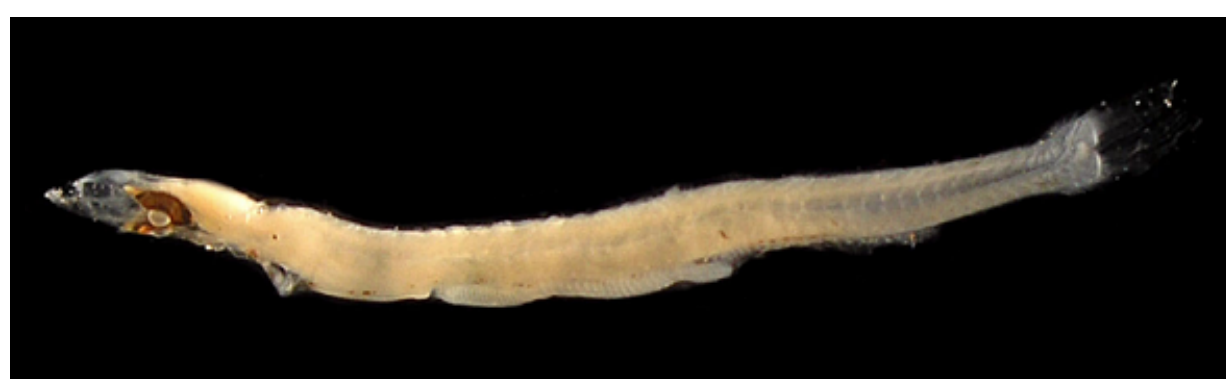

Figura 65 - B: DZUFRJ 14267; Flexão; CP 9,6 mm.

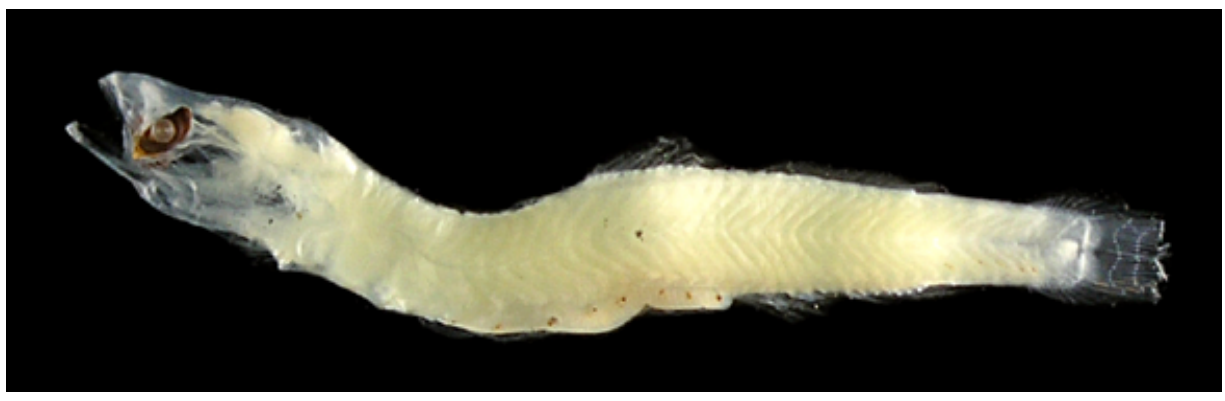

Figura 65 - C: DZUFRJ 1211; Pós-flexão; CP 14,5 mm. 


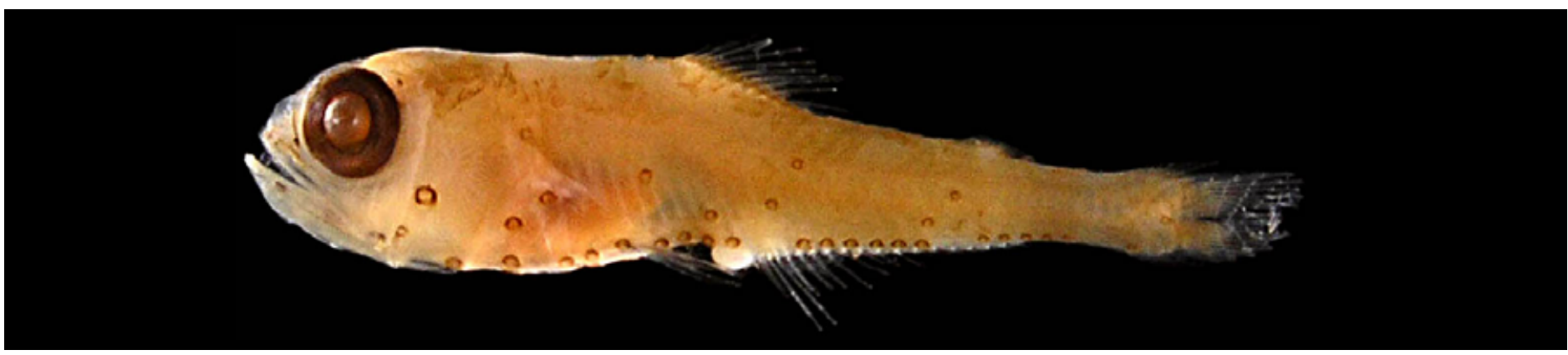

Figura 65 - D: DZUFRJ 22088; Juvenil; CP 16,0 mm.

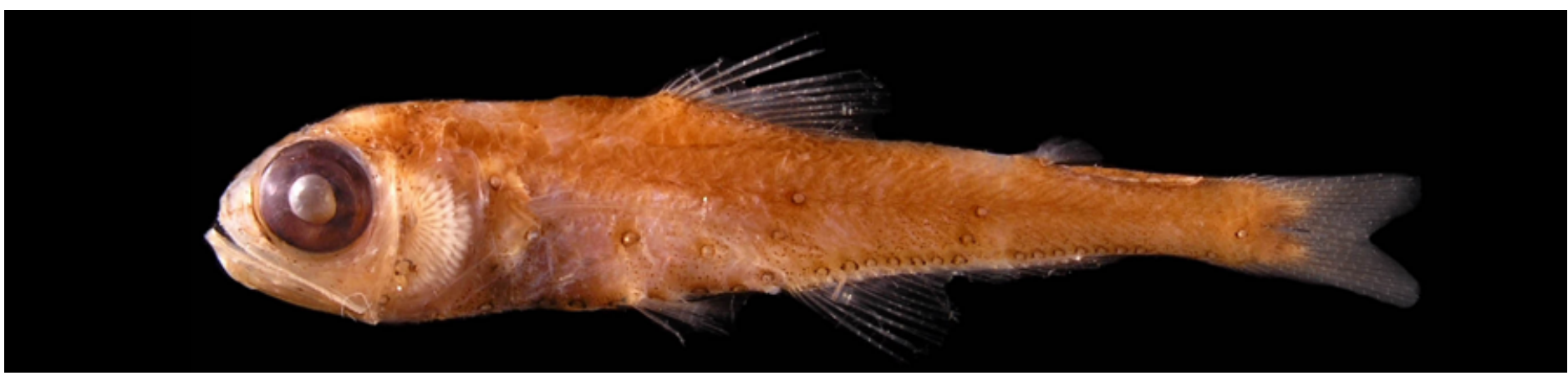

Figura 65 - E: DZUFRJ 7574; Adulto; CP 36,0 mm.

\section{Georreferenciamento}

\begin{tabular}{|c|c|c|c|c|c|c|c|c|}
\hline DZUFRJ & Latitude (S) & Longitude (W) & Data & $\begin{array}{l}\text { Tipo de } \\
\text { arrasto }\end{array}$ & $\begin{array}{l}\text { Profundidade } \\
\text { de coleta }\end{array}$ & Rede & $\begin{array}{c}\text { Malha } \\
(\mu \mathrm{m})\end{array}$ & $\begin{array}{l}N^{\circ} \text {. de } \\
\text { inds. }\end{array}$ \\
\hline 1179 & $22^{\circ} 07^{\prime} 29,0^{\prime \prime}$ & $039^{\circ} 06^{\prime} 23,5^{\prime \prime}$ & $10 / 05 / 2002$ & oblíquo & $1.000 \mathrm{~m}$ & cilíndrico-cônica & 500 & 1 \\
\hline 1211 & $22^{\circ} 02^{\prime} 30,0^{\prime \prime}$ & $039^{\circ} 49^{\prime} 41,2^{\prime \prime}$ & $12 / 05 / 2002$ & oblíquo & $1.000 \mathrm{~m}$ & cilíndrico-cônica & 500 & 2 \\
\hline 1249 & $22^{\circ} 08^{\prime} 17,5^{\prime \prime}$ & $039^{\circ} 46^{\prime} 28,5^{\prime \prime}$ & $11 / 05 / 2002$ & oblíquo & $1.000 \mathrm{~m}$ & cilíndrico-cônica & 500 & 1 \\
\hline 5519 & $22^{\circ} 31^{\prime} 58,9^{\prime \prime}$ & $040^{\circ} 02^{\prime} 53,4^{\prime \prime}$ & $07 / 11 / 2001$ & oblíquo & $1.000 \mathrm{~m}$ & cilíndrico-cônica & 500 & 2 \\
\hline 5521 & $22^{\circ} 31^{\prime} 40,9^{\prime \prime}$ & $040^{\circ} 02^{\prime} 39,6^{\prime \prime}$ & $07 / 11 / 2001$ & oblíquo & $1.000 \mathrm{~m}$ & cilíndrico-cônica & 500 & 3 \\
\hline 5525 & $22^{\circ} 31^{\prime} 58,9^{\prime \prime}$ & $040^{\circ} 02^{\prime} 53,4^{\prime \prime}$ & $07 / 11 / 2001$ & oblíquo & $1.000 \mathrm{~m}$ & cilíndrico-cônica & 500 & 1 \\
\hline 5526 & $22^{\circ} 32^{\prime} 49,0^{\prime \prime}$ & $040^{\circ} 04^{\prime} 20,9^{\prime \prime}$ & $07 / 11 / 2001$ & oblíquo & $1.000 \mathrm{~m}$ & cilíndrico-cônica & 500 & 1 \\
\hline 5527 & $22^{\circ} 32^{\prime} 49,0^{\prime \prime}$ & $040^{\circ} 04^{\prime} 20,9^{\prime \prime}$ & $07 / 11 / 2001$ & oblíquo & $1.000 \mathrm{~m}$ & cilíndrico-cônica & 500 & 3 \\
\hline 5530 & $22^{\circ} 31^{\prime} 40,9^{\prime \prime}$ & $040^{\circ} 02^{\prime} 39,6^{\prime \prime}$ & $07 / 11 / 2001$ & oblíquo & $1.000 \mathrm{~m}$ & cilíndrico-cônica & 500 & 4 \\
\hline 7381 & $21^{\circ} 58^{\prime} 31,0^{\prime \prime}$ & $039^{\circ} 50^{\prime} 29,7^{\prime \prime}$ & $10 / 10 / 2001$ & oblíquo & $1.000 \mathrm{~m}$ & cilíndrico-cônica & 500 & 10 \\
\hline 7387 & $21^{\circ} 54^{\prime} 36,5^{\prime \prime}$ & $039^{\circ} 45^{\prime} 20,0^{\prime \prime}$ & $10 / 10 / 2001$ & oblíquo & $1.000 \mathrm{~m}$ & cilíndrico-cônica & 500 & 5 \\
\hline 7389 & $21^{\circ} 54^{\prime} 36,5^{\prime \prime}$ & $039^{\circ} 45^{\prime} 20,0^{\prime \prime}$ & $09 / 10 / 2001$ & oblíquo & $1.000 \mathrm{~m}$ & cilíndrico-cônica & 500 & 2 \\
\hline 7391 & $21^{\circ} 53^{\prime} 10,4^{\prime \prime}$ & $039^{\circ} 45^{\prime} 49,9^{\prime \prime}$ & $10 / 10 / 2001$ & oblíquo & $1.000 \mathrm{~m}$ & cilíndrico-cônica & 500 & 1 \\
\hline 7563 & $21^{\circ} 54^{\prime} 36,5^{\prime \prime}$ & $039^{\circ} 45^{\prime} 20,0^{\prime \prime}$ & $10 / 10 / 2001$ & oblíquo & $1.000 \mathrm{~m}$ & cilíndrico-cônica & 500 & 8 \\
\hline 7566 & $21^{\circ} 58^{\prime} 31,0^{\prime \prime}$ & $039^{\circ} 50^{\prime} 29,7^{\prime \prime}$ & $11 / 10 / 2001$ & oblíquo & $1.000 \mathrm{~m}$ & cilíndrico-cônica & 500 & 12 \\
\hline 7570 & $21^{\circ} 58^{\prime} 31,0^{\prime \prime}$ & $039^{\circ} 50^{\prime} 29,7^{\prime \prime}$ & $10 / 10 / 2001$ & oblíquo & $1.000 \mathrm{~m}$ & cilíndrico-cônica & 500 & 5 \\
\hline 7574 & $21^{\circ} 57^{\prime} 10,5^{\prime \prime}$ & $039^{\circ} 43^{\prime} 33,3^{\prime \prime}$ & $09 / 10 / 2001$ & oblíquo & $1.000 \mathrm{~m}$ & cilíndrico-cônica & 500 & 3 \\
\hline 22063 & $22^{\circ} 02,27^{\prime}$ & $039^{\circ} 43,49^{\prime}$ & $18 / 06 / 2003$ & vertical & $90 \mathrm{~m}$ & cilíndrico-cônica & 500 & 1 \\
\hline 22087 & $22^{\circ} 32^{\prime} 50,0^{\prime \prime}$ & $040^{\circ} 04^{\prime} 09,9 "$ & $06 / 11 / 2001$ & oblíquo & $1.000 \mathrm{~m}$ & cilíndrico-cônica & 500 & 1 \\
\hline 22088 & $22^{\circ} 31^{\prime} 40,9^{\prime \prime}$ & $040^{\circ} 02^{\prime} 39,6^{\prime \prime}$ & $07 / 11 / 2001$ & oblíquo & $1.000 \mathrm{~m}$ & cilíndrico-cônica & 500 & 8 \\
\hline 22168 & $21^{\circ} 53^{\prime} 10,4^{\prime \prime}$ & $039^{\circ} 45^{\prime} 49,9^{\prime \prime}$ & $10 / 10 / 2001$ & oblíquo & $1.000 \mathrm{~m}$ & cilíndrico-cônica & 500 & 2 \\
\hline 22170 & $22^{\circ} 02,27^{\prime}$ & $039^{\circ} 43,49^{\prime}$ & $18 / 06 / 2003$ & vertical & $100-480 m$ & cilíndrico-cônica & 500 & 1 \\
\hline
\end{tabular}

Referências: Nafpakititis et al., 1977; Moser \& Ahlstrom, 1996; Castro \& Bonecker, 2006c; Moser \& Watson, 2006; Fahay, 2007; Santos \& Figueiredo, 2008. 


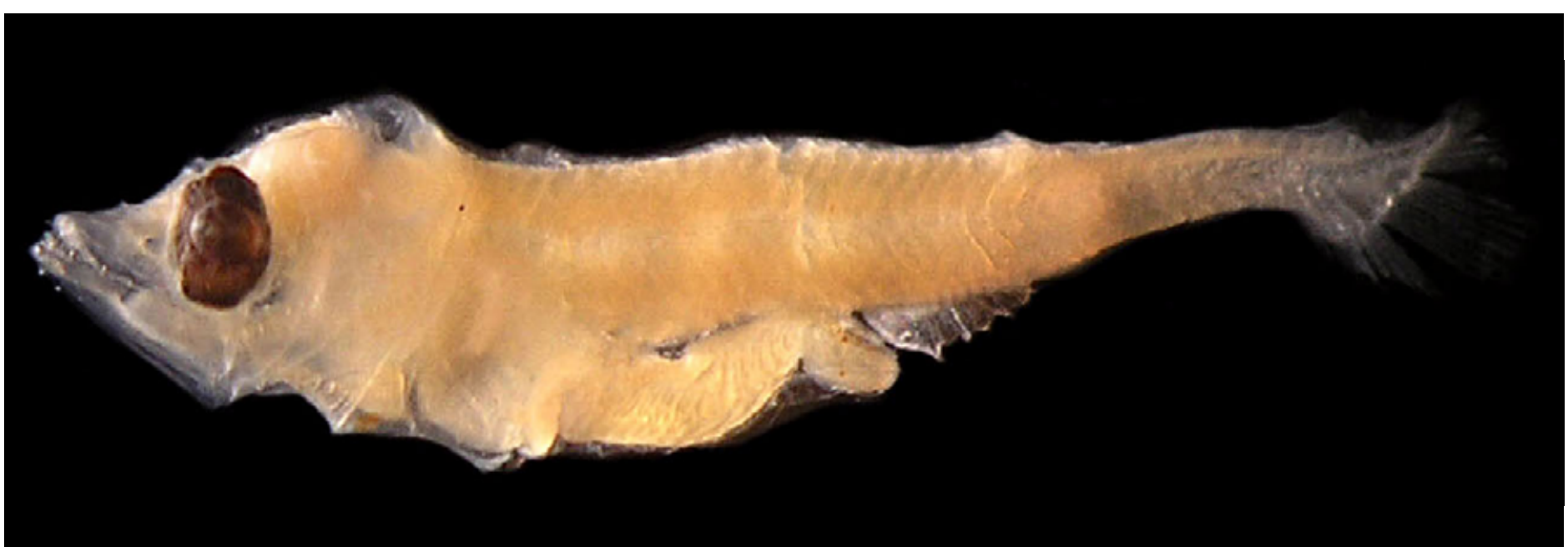

Figura 66: Hygophum taaningi. DZUFRJ 22785; Flexão; CP 5,1 mm.

\section{Hygophum taaningi Becker, 1965}

Possui olhos moderadamente elípticos sem tecido coroide, maiores e mais largos que nas outras espécies de Hygophum. O corpo é relativamente mais alto e comprimido lateralmente em comparação com outras espécies desse gênero. Durante a flexão possui um par de pigmentos na margem anterolateral da maxila inferior, um par no istmo, no cleitro e no final do intestino, próximo ao ânus. O número de miômeros varia entre 35 e 36.

Tamanho: flexão 5,1 mm.

Habitat: espécie marinha, epi-mesopelágica, ocorre em águas tropicais e subtropicais entre 475 e $1.000 \mathrm{~m}$ de profundidade durante o dia. A noite ocorre desde próximo à superfície até $125 \mathrm{~m}$ de profundidade.

Nome vulgar: Peixe-lanterna.

\section{Georreferenciamento}

\begin{tabular}{|c|c|c|c|c|c|c|c|c|}
\hline DZUFRJ & Latitude (S) & Longitude (W) & Data & $\begin{array}{c}\text { Tipo de } \\
\text { arrasto }\end{array}$ & $\begin{array}{c}\text { Profundidade } \\
\text { de coleta }\end{array}$ & Rede & $\begin{array}{c}\text { Malha } \\
(\boldsymbol{\mu m})\end{array}$ & $\begin{array}{c}\text { No. de } \\
\text { inds. }\end{array}$ \\
\hline 22785 & $22^{\circ} 07^{\prime} 29,0^{\prime \prime}$ & $039^{\circ} 06^{\prime} 235^{\prime \prime}$ & $10 / 05 / 2002$ & oblíquo & $1.000 \mathrm{~m}$ & cilíndrico-cônica & 500 & 1 \\
\hline
\end{tabular}

Referências: Moser \& Ahlstrom, 1996; Castro \& Bonecker, 2006c; Moser \& Watson, 2006; Fahay, 2007. 


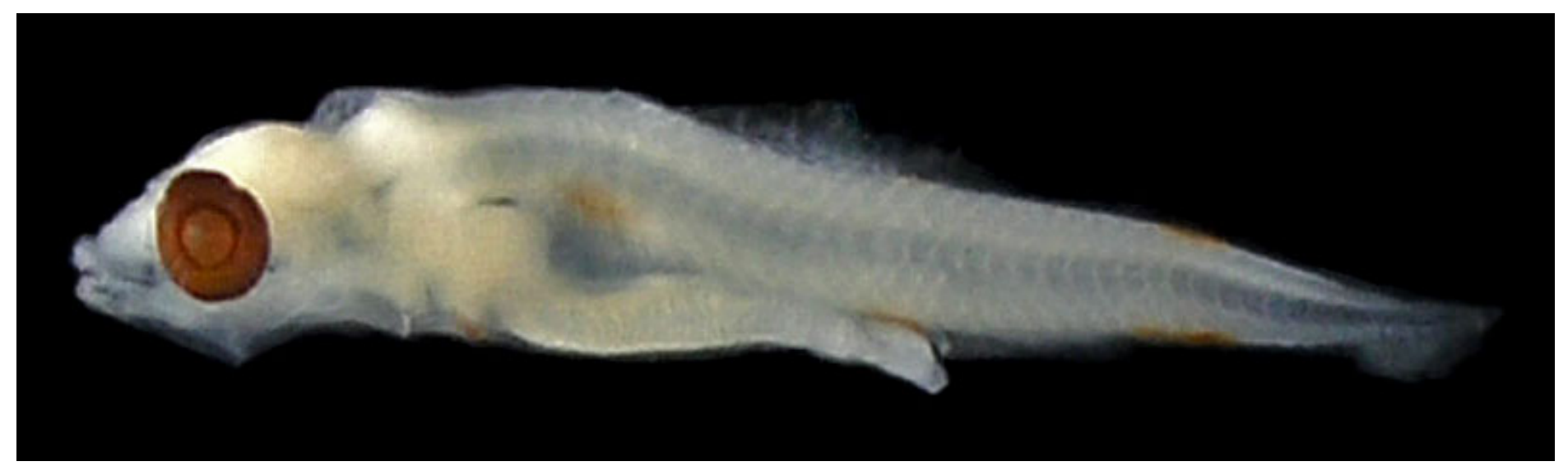

Figura 67: Lampadena sp. 1. DZUFRJ 22160; Pré-flexão; CP 5,0 mm.

\section{Lampadena sp. 1}

As larvas de Lampadena coletadas possuem, durante o período de pré-flexão, pigmentos nas margens dorsal e ventral do corpo na região da cauda; sobre a margem posterior do intestino, próximo ao ânus; na área da vesícula gasosa e um cromatóforo estrelado na margem ventral anterior do intestino. O número de miômeros varia entre 35 e 38. No Brasil já foram coletadas as espécies Lampadena anomala Parr, 1928; Lampadena chavesi Collett, 1905; Lampadena luminosa (Garman, 1899); Lampadena notialis Nafpaktitis \& Paxton, 1968 e Lampadena speculigera Goode \& Bean, 1896.

Tamanho: pré-flexão 3,5-6,1 mm.

Habitat: as espécies de Lampadena são marinhas, mesopelágicas, podendo ocorrer até $2.000 \mathrm{~m}$ de profundidade. Algumas espécies migram durante a noite para próximo da superfície.

Nome vulgar: Peixe-lanterna.

\section{Georreferenciamento}

\begin{tabular}{|c|c|c|c|c|c|c|c|c|}
\hline DZUFR & Latitude (S) & Longitude (W) & Data & $\begin{array}{c}\text { Tipo de } \\
\text { arrasto }\end{array}$ & $\begin{array}{c}\text { Profundidade } \\
\text { de coleta }\end{array}$ & Rede & $\begin{array}{c}\text { Malha } \\
(\boldsymbol{\mu m})\end{array}$ & $\begin{array}{c}\mathbf{N}^{\circ} \text {. de } \\
\text { inds. }\end{array}$ \\
\hline 22042 & $22^{\circ} 06^{\prime} 52,3^{\prime \prime}$ & $039^{\circ} 48^{\prime} 46,2^{\prime \prime}$ & $11 / 05 / 2002$ & oblíquo & até a termoclina & bongô & 500 & 1 \\
\hline 22056 & $22^{\circ} 06^{\prime} 52,3^{\prime \prime}$ & $039^{\circ} 48^{\prime} 46,2^{\prime \prime}$ & $11 / 05 / 2002$ & oblíquo & até a termoclina & bongô & 330 & 2 \\
\hline 22158 & $22^{\circ} 02^{\prime} 30,0^{\prime \prime}$ & $09^{\circ} 49^{\prime} 41,2^{\prime \prime}$ & $12 / 05 / 2002$ & oblíquo & até a termoclina & bongô & 330 & 1 \\
\hline 22160 & $22^{\circ} 02^{\prime} 30,0^{\prime \prime}$ & $039^{\circ} 49^{\prime} 41,2^{\prime \prime}$ & $12 / 05 / 2002$ & oblíquo & até a termoclina & bongô & 500 & 1 \\
\hline 22787 & $22^{\circ} 08^{\prime} 14,9^{\prime \prime}$ & $039^{\circ} 46^{\prime} 34,6^{\prime \prime}$ & $11 / 05 / 2002$ & oblíquo & até a termoclina & bongô & 330 & 1 \\
\hline
\end{tabular}

Referências: Moser \& Ahlstrom, 1996; Castro \& Bonecker, 2006c; Moser \& Watson, 2006. 


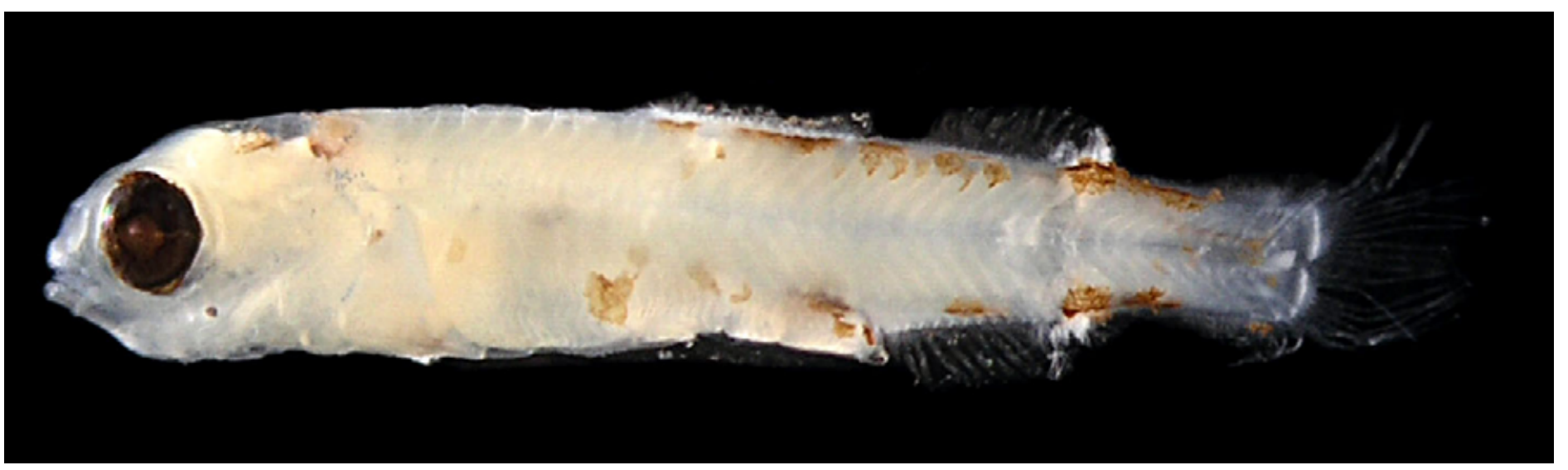

Figura 68: Lampadena sp. 2. . DZUFRJ 22167; Flexão; CP 7,6 mm.

\section{Lampadena sp. 2}

Possui fotóforo abaixo do olho na região posterior; pigmentos na cabeça, na região dorsal do corpo desde a base da nadadeira dorsal até o pedúnculo caudal. Possui ainda pigmentos na região do intestino e ânus, na base da nadadeira anal e no pedúnculo caudal. O número de miômeros varia entre 35 e 38. No Brasil já foram coletadas as espécies Lampadena anomala Parr, 1928; Lampadena chavesi Collett, 1905; Lampadena luminosa (Garman, 1899); Lampadena notialis Nafpaktitis \& Paxton, 1968 e Lampadena speculigera Goode \& Bean, 1896.

Tamanho: flexão 7,6 mm.

Habitat: as espécies de Lampadena são marinhas, mesopelágicas, podendo ocorrer até $2.000 \mathrm{~m}$ de profundidade. Algumas espécies migram durante a noite para próximo da superfície.

Nome vulgar: Peixe-lanterna.

\section{Georreferenciamento}

\begin{tabular}{|c|c|c|c|c|c|c|c|c|}
\hline DZUFRJ & Latitude (S) & Longitude (W) & Data & $\begin{array}{c}\text { Tipo de } \\
\text { arrasto }\end{array}$ & $\begin{array}{c}\text { Profundidade } \\
\text { de coleta }\end{array}$ & Rede & $\begin{array}{c}\text { Malha } \\
(\boldsymbol{\mu m})\end{array}$ & $\begin{array}{c}\mathbf{N}^{\circ} \text {. de } \\
\text { inds. }\end{array}$ \\
\hline 22167 & $2^{\circ} 57^{\prime} 5^{\prime}$ & $039^{\circ} 49,57^{\prime}$ & $19 / 06 / 2003$ & horizontal & superfície & nêuston & 500 & 1 \\
\hline
\end{tabular}

Referências: Moser \& Ahlstrom, 1996; Castro \& Bonecker, 2006c; Moser \& Watson, 2006. 


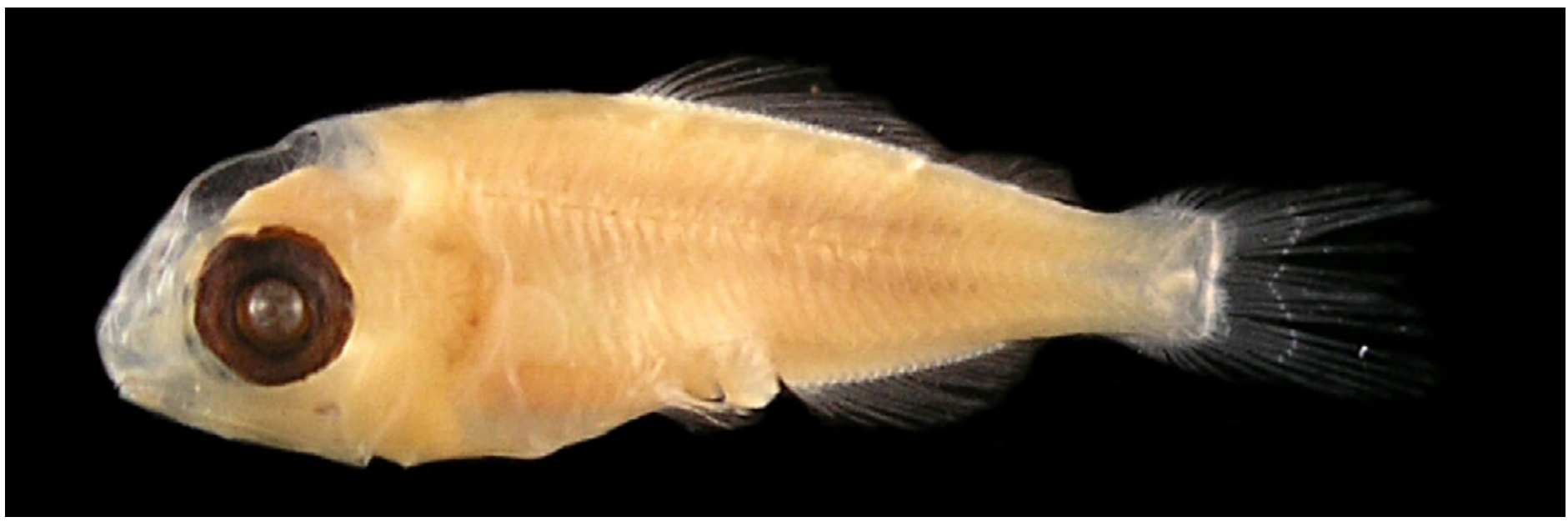

Figura 69 - A: Lampanyctus alatus. DZUFRJ 22788; Pós-flexão; CP 7,8 mm.

\section{Lampanyctus alatus Goode \& Bean, 1896}

O intestino é curto e muito flexionado, a cabeça é relativamente grande. Possui pigmentos na região dorsal da cabeça, na base da nadadeira peitoral, no intestino e

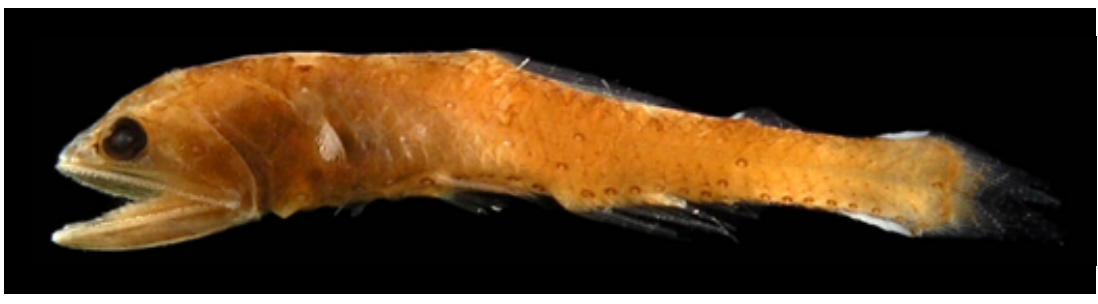

Figura 69 - B: DZUFRJ 22163; Juvenil; CP 16,5 mm. na ponta do focinho. O número de miômeros varia entre 33 e 36. Os indivíduos em transformação possuem fotóforos secundários na cabeça e na região entre a nadadeira pélvica e o pedúnculo caudal, glândula infracaudal curta e glândula luminosa na origem da nadadeira adiposa. Possui 6 (5 a 7) AOa e 5 a 7 (8) AOp; rastros branquiais do primeiro arco 4 (3) + $1+9$ (10).

Tamanho: pós-flexão 7,8 mm; juvenil 16,5 mm.

Habitat: espécie marinha, epi-mesopelágica, ocorre em águas tropicais e subtropicais entre 275 e $1.000 \mathrm{~m}$ de profundidade durante o dia. A noite ocorre entre 40 e 275 m de profundidade.

Nome vulgar: Peixe-lanterna.

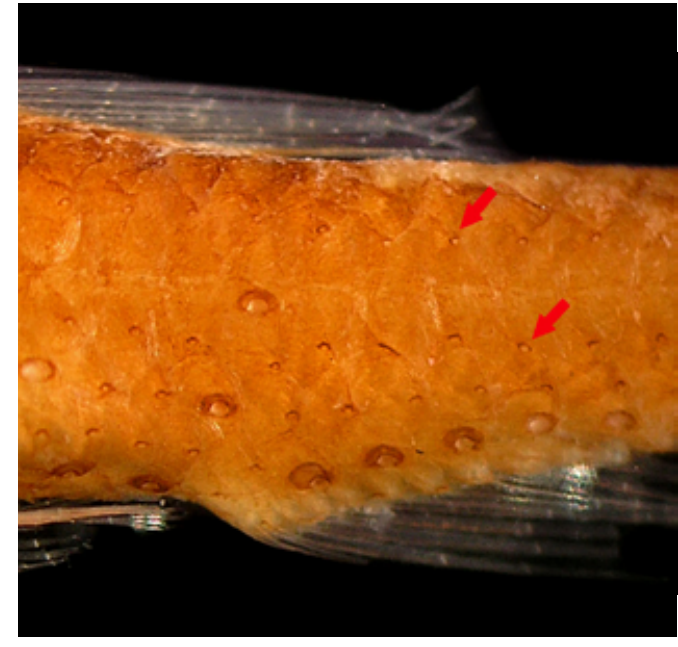

Figura 69 - C: Fotóforos secundários no tronco.

\section{Georreferenciamento}

\begin{tabular}{|c|c|c|c|c|c|c|c|c|}
\hline DZUFR & Latitude (S) & Longitude (W) & Data & $\begin{array}{c}\text { Tipo de } \\
\text { arrasto }\end{array}$ & $\begin{array}{c}\text { Profundidade } \\
\text { de coleta }\end{array}$ & Rede & $\begin{array}{c}\text { Malha } \\
\text { ( } \boldsymbol{\mu m})\end{array}$ & $\begin{array}{c}\mathbf{N}^{\circ} \text {. de } \\
\text { inds. }\end{array}$ \\
\hline 22163 & $21^{\circ} 54^{\prime} 36,5^{\prime \prime}$ & $039^{\circ} 45^{\prime} 20,0^{\prime \prime}$ & $10 / 10 / 2001$ & oblíquo & $1.000 \mathrm{~m}$ & cilíndrico-cônica & 500 & 1 \\
\hline 22788 & $21^{\circ} 58^{\prime} 31,0^{\prime \prime}$ & $039^{\circ} 50^{\prime} 29,7^{\prime \prime}$ & $10 / 10 / 2001$ & oblíquo & $1.000 \mathrm{~m}$ & cilíndrico-cônica & 500 & 1 \\
\hline
\end{tabular}

Referências: Nafpakititis et al., 1977; Moser \& Watson, 2006; Fahay, 2007; Santos \& Figueiredo, 2008. 


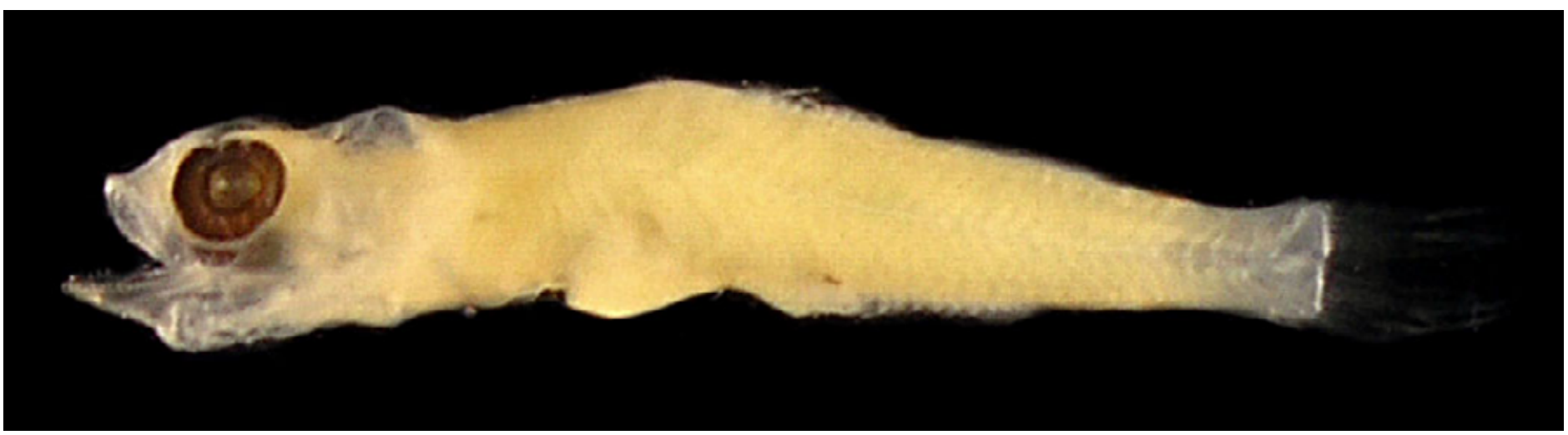

Figura 70 - A: Lepidophanes gaussi. DZUFRJ 22034; Flexão; CP 6,0 mm.

\section{Lepidophanes gaussi (Brauer, 1906)}

Possui corpo alongado (35 a 36 miômeros) e olhos redondos grandes. O intestino é longo e alcança a metade do corpo. As larvas no estágio de flexão possuem um pigmento dorsal e dois ventrais na região posterior do corpo. No estágio de pós-flexão, as larvas possuem dois pigmentos dorsais e dois ventrais na região da cauda, um no ânus, um abaixo da base da nadadeira peitoral, um na margem superior do opérculo e um na região occipital. O número de miômeros varia entre 35 e 36. Os indivíduos em transformação possuem 5 (6) AOa; 6 (5) AOp; 2 Pol; 4 Prc. A presença de tecido luminoso nas bases das nadadeiras peitoral e ventral e o número de rastros branquiais $(3+1$ + 8) separam essa espécie de L. guentheri.

Tamanho: flexão 5,6-6,7 mm; pós-flexão 7,0-9,2 mm; transformação 13,4-14,0 mm; juvenil 23,5-27,5 mm; adulto 31,5 mm.

Habitat: espécie marinha, epi-mesopelágica, ocorre em águas subtropicais entre 425 e $850 \mathrm{~m}$ de profundidade durante o dia. A noite ocorre desde próximo à superfície até $175 \mathrm{~m}$ de profundidade.

Nome vulgar: Peixe-lanterna.

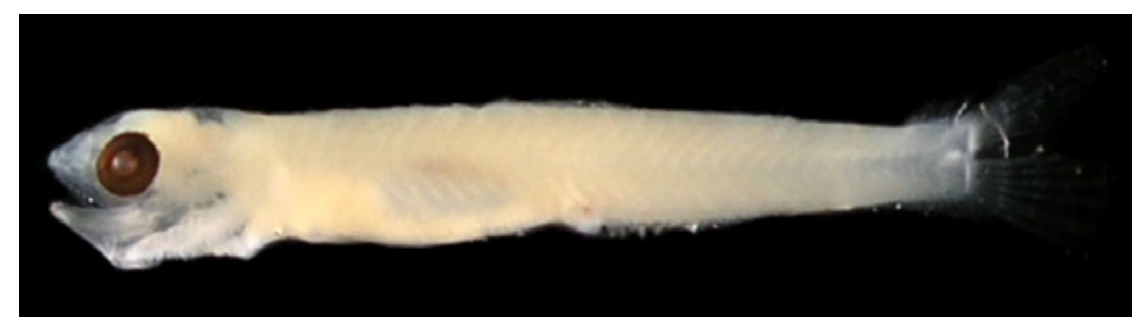

Figura 70 - B: DZUFRJ 22145; Pós-flexão; CP 9,2 mm.

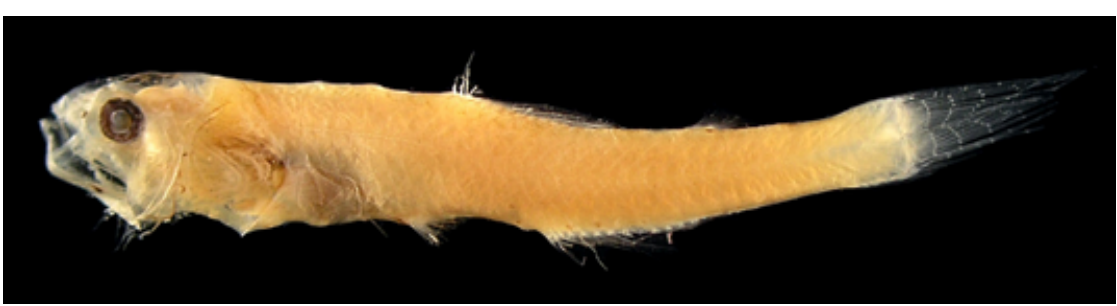

Figura 70 - C: DZUFRJ 21986; Transformação; CP 14,0 mm.

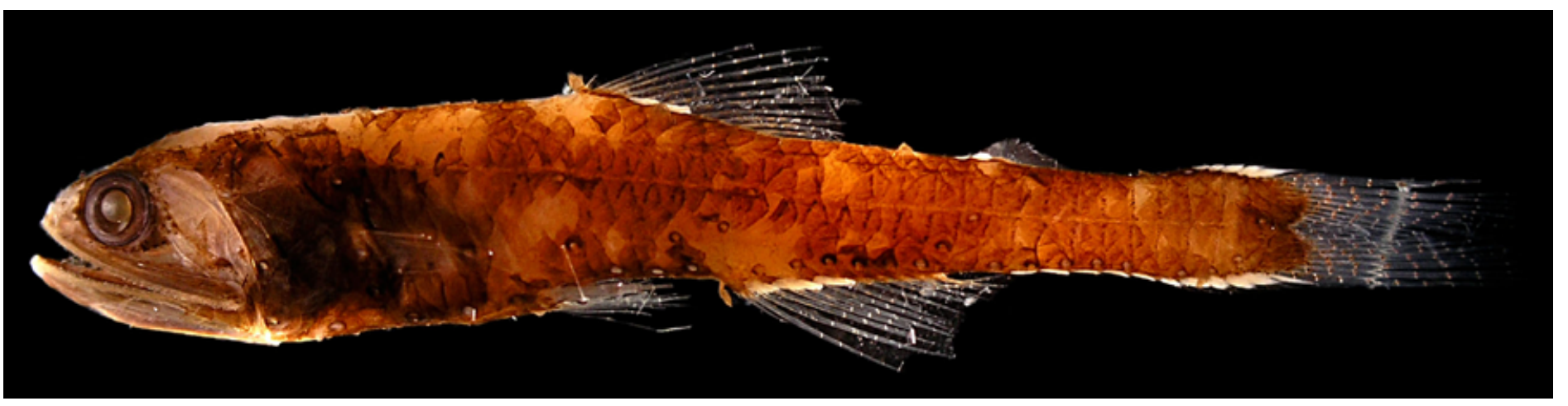

Figura 70 - D: DZUFRJ 22777; Juvenil; CP 27,5 mm. 


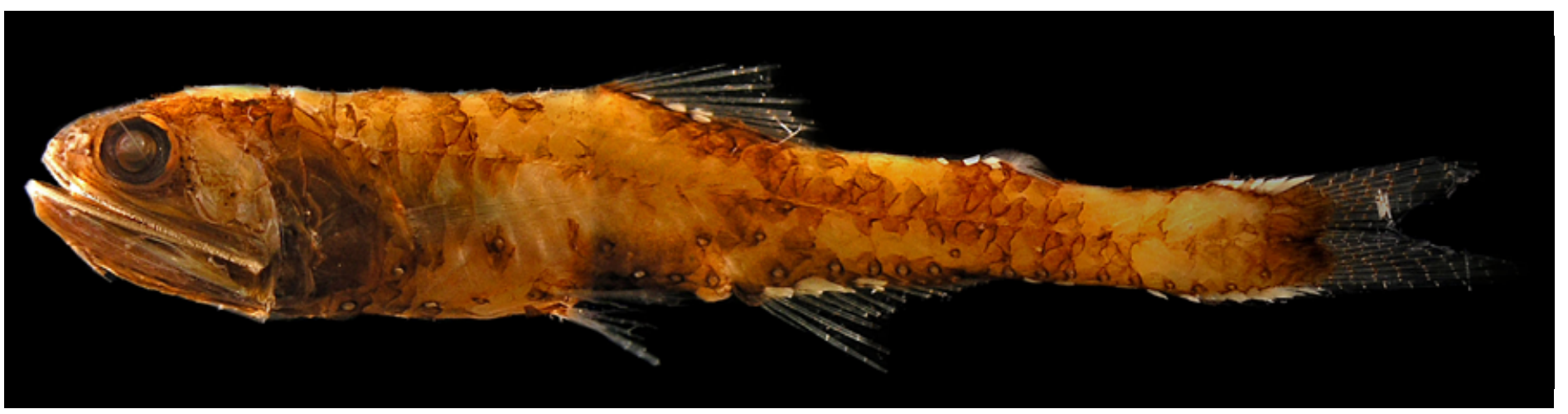

Figura 70 - E: DZUFRJ 22770; Adulto; CP 31,5 mm.

\section{Georreferenciamento}

\begin{tabular}{|c|c|c|c|c|c|c|c|c|}
\hline DZUFRJ & Latitude (S) & Longitude (W) & Data & $\begin{array}{l}\text { Tipo de } \\
\text { arrasto }\end{array}$ & $\begin{array}{c}\text { Profundidade } \\
\text { de coleta }\end{array}$ & Rede & $\begin{array}{l}\text { Malha } \\
(\mu \mathrm{m})\end{array}$ & $\begin{array}{l}N^{\circ} \text {. de } \\
\text { inds. }\end{array}$ \\
\hline 21986 & $21^{\circ} 57^{\prime} 10,5^{\prime \prime}$ & $039^{\circ} 43^{\prime} 33,3^{\prime \prime}$ & 09/10/2001 & oblíquo & $1.000 \mathrm{~m}$ & cilíndrico-cônica & 500 & 3 \\
\hline 21988 & $21^{\circ} 58^{\prime} 31,0^{\prime \prime}$ & $039^{\circ} 50^{\prime 29,7 "}$ & $10 / 10 / 2001$ & oblíquo & $1.000 \mathrm{~m}$ & cilíndrico-cônica & 500 & 1 \\
\hline 22017 & $22^{\circ} 08^{\prime} 14,9^{\prime \prime}$ & $039^{\circ} 46^{\prime} 34,6^{\prime \prime}$ & $11 / 05 / 2002$ & oblíquo & até a termoclina & bongô & 500 & 3 \\
\hline 22029 & $22^{\circ} 03^{\prime} 03,3^{\prime \prime}$ & $039^{\circ} 50^{\prime} 39,0^{\prime \prime}$ & $10 / 05 / 2002$ & oblíquo & até a termoclina & bongô & 500 & 1 \\
\hline 22032 & $22^{\circ} 06^{\prime} 37,8^{\prime \prime}$ & $039^{\circ} 49^{\prime} 44,8^{\prime \prime}$ & $10 / 05 / 2002$ & oblíquo & até a termoclina & bongô & 500 & 2 \\
\hline 22034 & $22^{\circ} 08^{\prime} 52,5^{\prime \prime}$ & $039^{\circ} 46^{\prime} 27,9^{\prime \prime}$ & $12 / 05 / 2002$ & oblíquo & até a termoclina & bongô & 500 & 1 \\
\hline 22038 & $22^{\circ} 07 ' 29,0^{\prime \prime}$ & $039^{\circ} 06^{\prime} 23,5^{\prime \prime}$ & $10 / 05 / 2002$ & oblíquo & $1.000 \mathrm{~m}$ & cilíndrico-cônica & 500 & 3 \\
\hline 22045 & $22^{\circ} 02^{\prime} 30,0^{\prime \prime}$ & $039^{\circ} 49^{\prime} 41,2^{\prime \prime}$ & $12 / 05 / 2002$ & oblíquo & até a termoclina & bongô & 500 & 2 \\
\hline 22046 & $21^{\circ} 53^{\prime} 10,4^{\prime \prime}$ & $039^{\circ} 45^{\prime} 49,9^{\prime \prime}$ & $10 / 10 / 2001$ & oblíquo & $1.000 \mathrm{~m}$ & cilíndrico-cônica & 500 & 1 \\
\hline 22094 & $22^{\circ} 37^{\prime} 35,5^{\prime \prime}$ & $040^{\circ} 09^{\prime} 32,8^{\prime \prime}$ & $16 / 05 / 2002$ & oblíquo & $1.000 \mathrm{~m}$ & cilíndrico-cônica & 500 & 2 \\
\hline 22095 & $22^{\circ} 33^{\prime} 47,7^{\prime \prime}$ & $040^{\circ} 12^{\prime} 20,5^{\prime \prime}$ & $17 / 05 / 2002$ & oblíquo & $50 \mathrm{~m}$ & bongô & 500 & 1 \\
\hline 22096 & $22^{\circ} 36^{\prime} 54,9^{\prime \prime}$ & $040^{\circ} 09^{\prime} 19,4^{\prime \prime}$ & $16 / 05 / 2002$ & oblíquo & $50 \mathrm{~m}$ & bongô & 500 & 1 \\
\hline 22097 & $22^{\circ} 31^{\prime} 58,9^{\prime \prime}$ & $040^{\circ} 02^{\prime} 53,4^{\prime \prime}$ & $07 / 11 / 2001$ & oblíquo & $1.000 \mathrm{~m}$ & cilíndrico-cônica & 500 & 1 \\
\hline 22145 & $22^{\circ} 31^{\prime} 40,9^{\prime \prime}$ & $040^{\circ} 02^{\prime} 39,6^{\prime \prime}$ & $07 / 11 / 2001$ & oblíquo & $1.000 \mathrm{~m}$ & cilíndrico-cônica & 500 & 2 \\
\hline 22770 & $21^{\circ} 53^{\prime} 10,4^{\prime \prime}$ & $039^{\circ} 45^{\prime} 49,9^{\prime \prime}$ & $10 / 10 / 2001$ & oblíquo & $1.000 \mathrm{~m}$ & cilíndrico-cônica & 500 & 1 \\
\hline 22777 & $21^{\circ} 53^{\prime} 10,4^{\prime \prime}$ & $039^{\circ} 45^{\prime} 49,9^{\prime \prime}$ & $10 / 10 / 2001$ & oblíquo & $1.000 \mathrm{~m}$ & cilíndrico-cônica & 500 & 1 \\
\hline 22782 & $21^{\circ} 58^{\prime} 31,0^{\prime \prime}$ & $039^{\circ} 50^{\prime} 29,7 "$ & $11 / 10 / 2001$ & oblíquo & $1.000 \mathrm{~m}$ & cilíndrico-cônica & 500 & 1 \\
\hline
\end{tabular}

Referências: Nafpakititis et al., 1977; Moser \& Ahlstrom, 1996; Castro \& Bonecker, 2006c; Moser \& Watson, 2006; Fahay, 2007; Santos \& Figueiredo, 2008. 


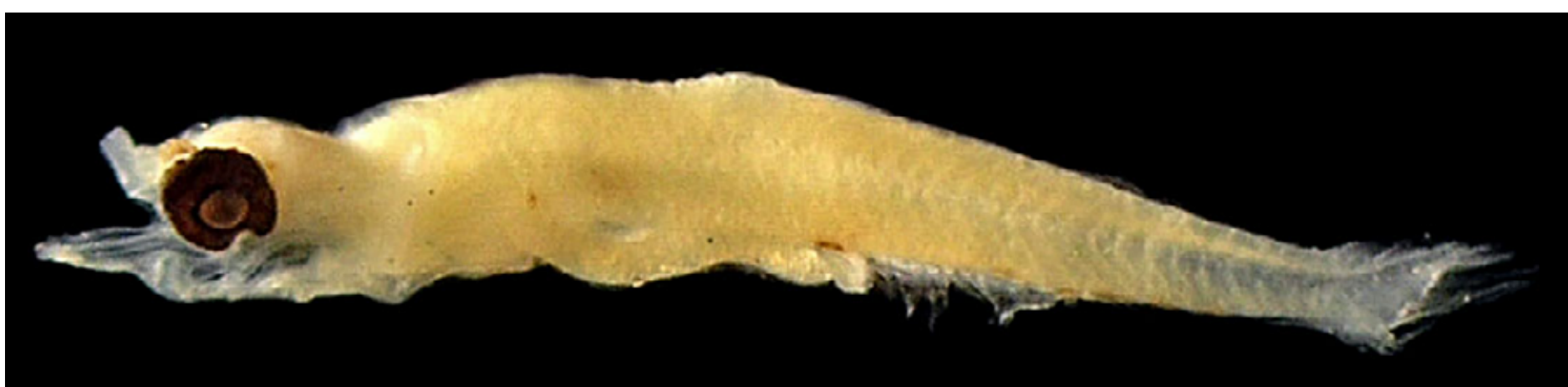

Figura 71 - A: Lepidophanes guentheri. A. DZUFRJ 22028; Flexão; CP 4,5 mm.

\section{Lepidophanes guentheri \\ (Goode \& Bean, 1896)}

Possui corpo alongado (36 miômeros) e olhos redondos grandes. O intestino é longo e alcança a metade do corpo. As larvas no estágio de flexão possuem três pigmentos dorsais e uma série ventral na região posterior do corpo. No estágio de pós-flexão as larvas possuem três pigmentos dorsais, três ventrais na região da cauda e um no ânus. Possui um fotóforo na base da nadadeira peitoral, um na região anterior e outro na região ventral do olho. Os indivíduos em transformação podem ser separadas das larvas de L. gaussi por apresentarem um número maior de rastros branquiais no primeiro arco e pela ausência de tecido luminoso na base da nadadeira peitoral. Rastros branquiais: $4+1+9$ a 10. Os juvenis possuem 2 Pol, 4 Prc formando um arco e Prc4 na altura da linha lateral, na base da nadadeira caudal; SAO bem angulado; 5 AOa (5 a 6) e 6 (5 a 7) AOp.

Tamanho: flexão 4,5-8,8 mm; pós-flexão 9,0-12,6 mm; transformação 13,4-17,3 mm; juvenil 18,0-31,5 mm; adulto 41,0-43,0 mm.

Habitat: espécie marinha, epi-mesopelágica, ocorre em águas tropicais e subtropicais entre 700 e $950 \mathrm{~m}$ de profundidade durante o dia. A noite ocorre entre 50 e $175 \mathrm{~m}$ de profundidade.

Nome vulgar: Peixe-lanterna.

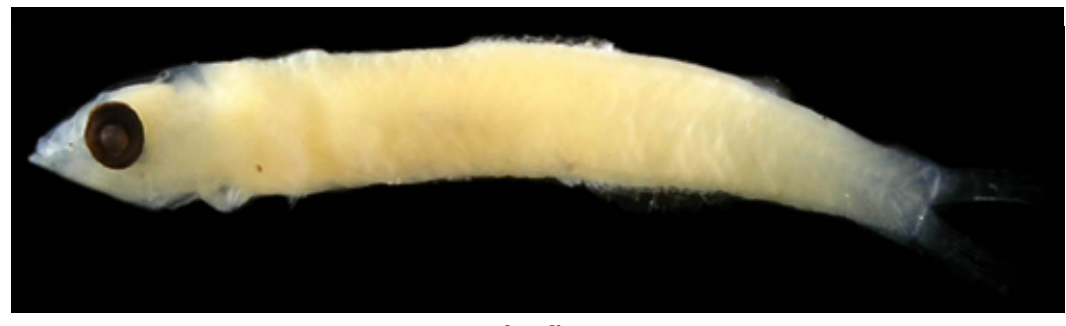

Figura 71 - B: DZUFRJ 22164; Pós-flexão; CP 11,3 mm.

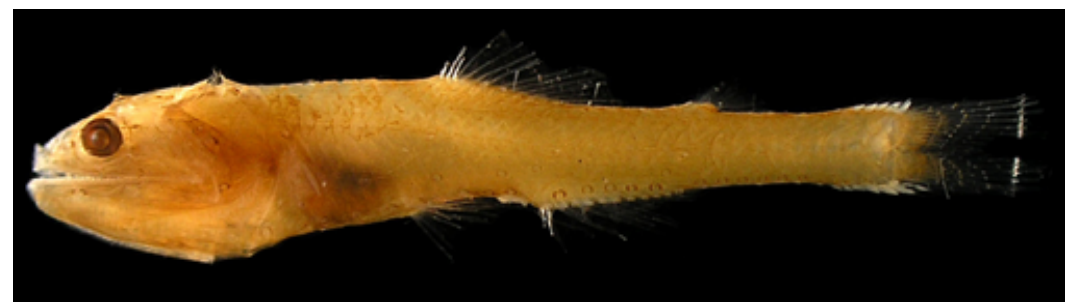

Figura 71 - C: DZUFRJ 22161; Transformação; CP 15,5 mm.

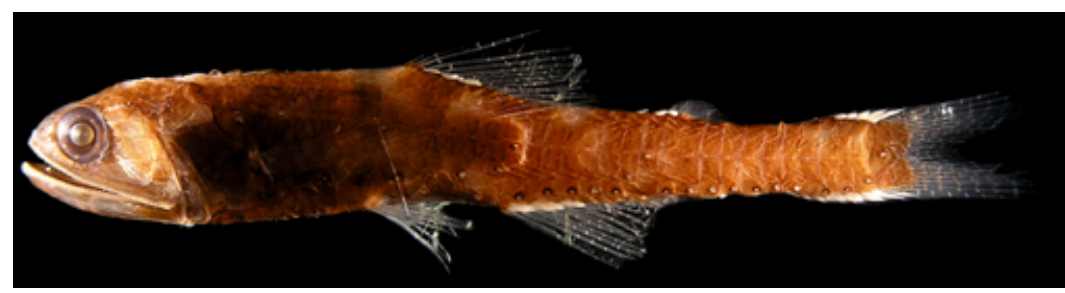

Figura 71 - D: DZUFRJ 7380; Juvenil; CP 31,5 mm.

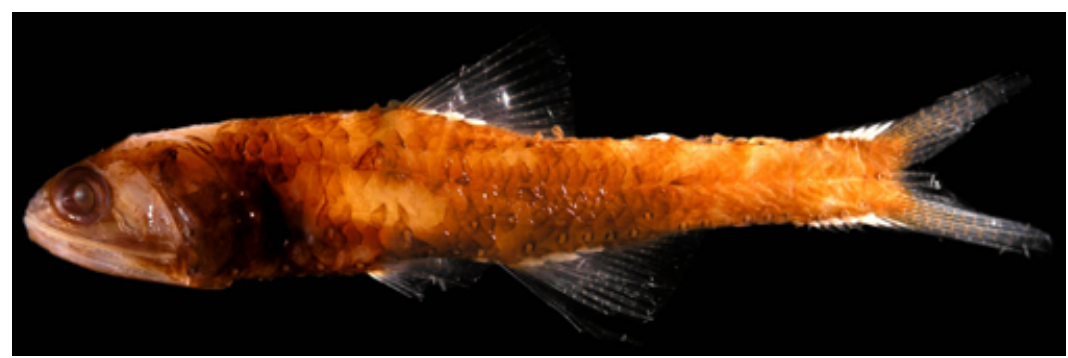

Figura 71 - E: DZUFRJ 5557; Adulto; CP 43,0 mm.

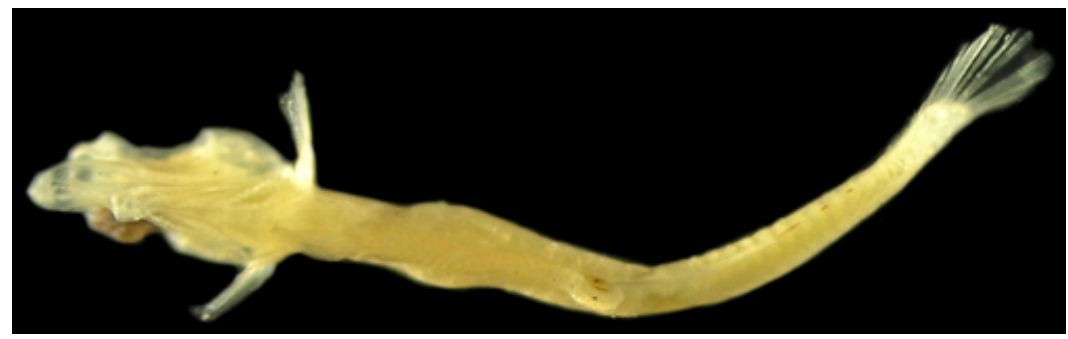

Figura 71 - F: Vista ventral durante a flexão. 


\section{Georreferenciamento}

\begin{tabular}{|c|c|c|c|c|c|c|c|}
\hline Latitude & Longitude & Data & $\begin{array}{l}\text { Tipo de } \\
\text { arrasto }\end{array}$ & $\begin{array}{l}\text { Profundidade } \\
\text { de coleta }\end{array}$ & Rede & $\begin{array}{l}\text { Malha } \\
(\mu \mathrm{m})\end{array}$ & $\begin{array}{l}\text { No. de } \\
\text { inds. }\end{array}$ \\
\hline $22^{\circ} 32^{\prime} 49,0^{\prime \prime}$ & $040^{\circ} 04^{\prime} 20,9^{\prime \prime}$ & $07 / 11 / 2001$ & oblíquo & $1.000 \mathrm{~m}$ & cilíndrico-cônica & 500 & 1 \\
\hline $22^{\circ} 31^{\prime} 40,9^{\prime \prime}$ & $040^{\circ} 02^{\prime} 39,6^{\prime \prime}$ & $07 / 11 / 2001$ & oblíquo & $1.000 \mathrm{~m}$ & cilíndrico-cônica & 500 & 2 \\
\hline $21^{\circ} 53^{\prime} 10,4^{\prime \prime}$ & $039^{\circ} 45^{\prime} 49,9^{\prime \prime}$ & $10 / 10 / 2001$ & oblíquo & $1.000 \mathrm{~m}$ & cilíndrico-cônica & 500 & 14 \\
\hline $21^{\circ} 57^{\prime} 10,5^{\prime \prime}$ & $039^{\circ} 43^{\prime} 33,3^{\prime \prime}$ & $09 / 10 / 2001$ & oblíquo & $1.000 \mathrm{~m}$ & cilíndrico-cônica & 500 & 1 \\
\hline $21^{\circ} 57^{\prime} 10,5^{\prime \prime}$ & $039^{\circ} 43^{\prime} 33,3^{\prime \prime}$ & 09/10/2001 & oblíquo & $1.000 \mathrm{~m}$ & cilíndrico-cônica & 500 & 3 \\
\hline $21^{\circ} 53^{\prime} 10,4^{\prime \prime}$ & $039^{\circ} 45^{\prime} 49,9^{\prime \prime}$ & $10 / 10 / 2001$ & oblíquo & $1.000 \mathrm{~m}$ & cilíndrico-cônica & 500 & 19 \\
\hline $21^{\circ} 57^{\prime} 10,5^{\prime \prime}$ & $039^{\circ} 43^{\prime} 33,3 "$ & 09/10/2001 & oblíquo & $1.000 \mathrm{~m}$ & cilíndrico-cônica & 500 & 7 \\
\hline $21^{\circ} 54^{\prime} 36,5^{\prime \prime}$ & $039^{\circ} 45^{\prime} 20,0^{\prime \prime}$ & 09/10/2001 & oblíquo & $1.000 \mathrm{~m}$ & cilíndrico-cônica & 500 & 4 \\
\hline $22^{\circ} 08^{\prime} 14,9^{\prime \prime}$ & $039^{\circ} 46^{\prime} 34,6^{\prime \prime}$ & $11 / 05 / 2002$ & oblíquo & até a termoclina & bongô & 330 & 14 \\
\hline $21^{\circ} 58^{\prime} 31,0^{\prime \prime}$ & $039^{\circ} 50^{\prime} 29,7^{\prime \prime}$ & $10 / 10 / 2001$ & oblíquo & $1.000 \mathrm{~m}$ & cilíndrico-cônica & 500 & 17 \\
\hline $21^{\circ} 54^{\prime} 36,5^{\prime \prime}$ & $039^{\circ} 45^{\prime} 20,0^{\prime \prime}$ & $10 / 10 / 2001$ & oblíquo & $1.000 \mathrm{~m}$ & cilíndrico-cônica & 500 & 23 \\
\hline $22^{\circ} 08^{\prime} 01,8^{\prime \prime}$ & $039^{\circ} 37^{\prime} 30,8^{\prime \prime}$ & $03 / 12 / 2002$ & vertical & $1.400-2.000 \mathrm{~m}$ & cilíndrico-cônica & 200 & 1 \\
\hline $22^{\circ} 35^{\prime} 08,5^{\prime \prime}$ & $039^{\circ} 46^{\prime} 22,3^{\prime \prime}$ & $06 / 12 / 2002$ & vertical & $50 \mathrm{~m}$ & cilíndrico-cônica & 200 & 4 \\
\hline $21^{\circ} 58^{\prime} 31,0^{\prime \prime}$ & $039^{\circ} 50^{\prime} 29,7^{\prime \prime}$ & $10 / 10 / 2001$ & oblíquo & $1.000 \mathrm{~m}$ & cilíndrico-cônica & 500 & 18 \\
\hline $21^{\circ} 58^{\prime} 31,0^{\prime \prime}$ & $039^{\circ} 50^{\prime} 29,7^{\prime \prime}$ & $11 / 10 / 2001$ & oblíquo & $1.000 \mathrm{~m}$ & cilíndrico-cônica & 500 & 7 \\
\hline $22^{\circ} 08^{\prime} 17,5^{\prime \prime}$ & $039^{\circ} 46^{\prime} 28,5^{\prime \prime}$ & $11 / 05 / 2002$ & oblíquo & $1.000 \mathrm{~m}$ & cilíndrico-cônica & 500 & 3 \\
\hline $21^{\circ} 54 ' 36,5^{\prime \prime}$ & $039^{\circ} 45^{\prime} 20,0^{\prime \prime}$ & $10 / 10 / 2001$ & oblíquo & $1.000 \mathrm{~m}$ & cilíndrico-cônica & 500 & 8 \\
\hline $21^{\circ} 53^{\prime} 10,4^{\prime \prime}$ & $039^{\circ} 45^{\prime} 49,9^{\prime \prime}$ & $10 / 10 / 2001$ & oblíquo & $1.000 \mathrm{~m}$ & cilíndrico-cônica & 500 & 8 \\
\hline $22^{\circ} 08^{\prime} 52,5^{\prime \prime}$ & $039^{\circ} 46^{\prime} 27,9^{\prime \prime}$ & $12 / 05 / 2002$ & oblíquo & até a termoclina & bongô & 500 & 2 \\
\hline $22^{\circ} 02^{\prime} 30,0^{\prime \prime}$ & $039^{\circ} 49^{\prime} 41,2^{\prime \prime}$ & $12 / 05 / 2002$ & oblíquo & até a termoclina & bongô & 330 & 43 \\
\hline $22^{\circ} 02^{\prime} 30,0^{\prime \prime}$ & $039^{\circ} 49^{\prime} 41,2^{\prime \prime}$ & $12 / 05 / 2002$ & oblíquo & $1.000 \mathrm{~m}$ & cilíndrico-cônica & 500 & 18 \\
\hline $22^{\circ} 08^{\prime} 52,5^{\prime \prime}$ & $039^{\circ} 46^{\prime} 27,9^{\prime \prime}$ & $12 / 05 / 2002$ & oblíquo & até a termoclina & bongô & 330 & 2 \\
\hline $22^{\circ} 07^{\prime} 29,0^{\prime \prime}$ & $039^{\circ} 06^{\prime} 23,5^{\prime \prime}$ & $10 / 05 / 2002$ & oblíquo & $1.000 \mathrm{~m}$ & cilíndrico-cônica & 500 & 231 \\
\hline $22^{\circ} 06^{\prime} 52,3^{\prime \prime}$ & $039^{\circ} 48^{\prime} 46,2^{\prime \prime}$ & $11 / 05 / 2002$ & oblíquo & $1.000 \mathrm{~m}$ & cilíndrico-cônica & 500 & 3 \\
\hline $22^{\circ} 08^{\prime} 14,9^{\prime \prime}$ & $039^{\circ} 46^{\prime} 34,6^{\prime \prime}$ & $11 / 05 / 2002$ & oblíquo & até a termoclina & bongô & 500 & 16 \\
\hline $22^{\circ} 03^{\prime} 03,3^{\prime \prime}$ & $039^{\circ} 50^{\prime} 39,0^{\prime \prime}$ & $10 / 05 / 2002$ & oblíquo & até a termoclina & bongô & 500 & 4 \\
\hline $22^{\circ} 06^{\prime} 52,3^{\prime \prime}$ & $039^{\circ} 48^{\prime} 46,2^{\prime \prime}$ & $11 / 05 / 2002$ & oblíquo & até a termoclina & bongô & 330 & 28 \\
\hline $22^{\circ} 43,56^{\prime}$ & $039^{\circ} 53,25^{\prime}$ & $14 / 06 / 2003$ & vertical & $60 \mathrm{~m}$ & cilíndrico-cônica & 500 & 1 \\
\hline $22^{\circ} 03^{\prime} 03,3^{\prime \prime}$ & $039^{\circ} 50^{\prime} 39,0^{\prime \prime}$ & $10 / 05 / 2002$ & oblíquo & até a termoclina & bongô & 330 & 9 \\
\hline $22^{\circ} 42^{\prime} 06,0^{\prime \prime}$ & $040^{\circ} 14 ' 26,0^{\prime \prime}$ & $19 / 05 / 2002$ & oblíquo & $50 \mathrm{~m}$ & bongô & 500 & 1 \\
\hline $22^{\circ} 38^{\prime} 29,0^{\prime \prime}$ & $040^{\circ} 17^{\prime} 40,0^{\prime \prime}$ & $18 / 05 / 2002$ & oblíquo & $800 \mathrm{~m}$ & cilíndrico-cônica & 500 & 2 \\
\hline $22^{\circ} 36^{\prime} 54,9^{\prime \prime}$ & $040^{\circ} 09^{\prime} 19,4^{\prime \prime}$ & $16 / 05 / 2002$ & oblíquo & $50 \mathrm{~m}$ & bongô & 500 & 3 \\
\hline $22^{\circ} 31^{\prime} 58,9$ & $040^{\circ} 02^{\prime} 53,4^{\prime \prime}$ & $07 / 11 / 2001$ & oblíquo & $1.000 \mathrm{~m}$ & cilíndrico-cônica & 500 & 1 \\
\hline $21^{\circ} 57,1^{\prime}$ & $039^{\circ} 37,32^{\prime}$ & $16 / 06 / 2003$ & vertical & $2.000 \mathrm{~m}$ & cilíndrico-cônica & 500 & 1 \\
\hline $22^{\circ} 02^{\prime} 35,2^{\prime \prime}$ & $039^{\circ} 43^{\prime} 18,2^{\prime \prime}$ & $04 / 12 / 2002$ & horizontal & superfície & nêuston & 500 & 2 \\
\hline $22^{\circ} 33^{\prime} 47,7^{\prime \prime}$ & $040^{\circ} 12^{\prime} 20,5^{\prime \prime}$ & $17 / 05 / 2002$ & oblíquo & $50 \mathrm{~m}$ & bongô & 500 & 6 \\
\hline $22^{\circ} 31^{\prime} 40,9^{\prime \prime}$ & $040^{\circ} 02^{\prime} 39,6^{\prime \prime}$ & $07 / 11 / 2001$ & oblíquo & $1.000 \mathrm{~m}$ & cilíndrico-cônica & 500 & 10 \\
\hline $22^{\circ} 33^{\prime} 45,8^{\prime \prime}$ & $040^{\circ} 13^{\prime} 22,9^{\prime \prime}$ & $17 / 05 / 2002$ & oblíquo & $800 \mathrm{~m}$ & cilíndrico-cônica & 500 & 11 \\
\hline $22^{\circ} 33^{\prime} 47,7^{\prime \prime}$ & $040^{\circ} 12^{\prime} 20,5^{\prime \prime}$ & $17 / 05 / 2002$ & oblíquo & $50 \mathrm{~m}$ & bongô & 330 & 13 \\
\hline $22^{\circ} 06^{\prime} 37,8^{\prime \prime}$ & $039^{\circ} 49^{\prime} 44,8^{\prime \prime}$ & $10 / 05 / 2002$ & oblíquo & até a termoclina & bongô & 330 & 84 \\
\hline $22^{\circ} 36^{\prime} 54,9^{\prime \prime}$ & $040^{\circ} 09^{\prime} 19,4^{\prime \prime}$ & $16 / 05 / 2002$ & oblíquo & $50 \mathrm{~m}$ & bongô & 330 & 24 \\
\hline $22^{\circ} 39,68^{\prime}$ & $040^{\circ} 03,24^{\prime}$ & $13 / 06 / 2003$ & vertical & $60 \mathrm{~m}$ & cilíndrico-cônica & 500 & 1 \\
\hline $22^{\circ} 31^{\prime} 40,9^{\prime \prime}$ & $040^{\circ} 02 ' 39,6^{\prime \prime}$ & 07/11/2001 & oblíquo & $1.000 \mathrm{~m}$ & cilíndrico-cônica & 500 & 2 \\
\hline $22^{\circ} 06^{\prime} 52,3^{\prime \prime}$ & $039^{\circ} 48^{\prime} 46,2^{\prime \prime}$ & $11 / 05 / 2002$ & oblíquo & até a termoclina & bongô & 500 & 4 \\
\hline $22^{\circ} 42^{\prime} 06,0^{\prime \prime}$ & $040^{\circ} 14^{\prime} 26^{\prime \prime}$ & $19 / 05 / 2002$ & oblíquo & $50 \mathrm{~m}$ & bongô & 330 & 1 \\
\hline $22^{\circ} 37^{\prime} 35,5^{\prime \prime}$ & $040^{\circ} 09^{\prime} 32,8^{\prime \prime}$ & $16 / 05 / 2002$ & oblíquo & $1.000 \mathrm{~m}$ & cilíndrico-cônica & 500 & 12 \\
\hline $22^{\circ} 31^{\prime} 58,9^{\prime \prime}$ & $040^{\circ} 02^{\prime} 53,4^{\prime \prime}$ & $07 / 11 / 2001$ & oblíquo & $1.000 \mathrm{~m}$ & cilíndrico-cônica & 500 & 5 \\
\hline $22^{\circ} 02^{\prime} 30,0^{\prime \prime}$ & $039^{\circ} 49^{\prime} 41,2^{\prime \prime}$ & $12 / 05 / 2002$ & oblíquo & até a termoclina & bongô & 500 & 19 \\
\hline $22^{\circ} 38^{\prime} 25,0^{\prime \prime}$ & $040^{\circ} 17^{\prime} 41,0^{\prime \prime}$ & $19 / 05 / 2002$ & oblíquo & $40 \mathrm{~m}$ & bongô & 330 & 2 \\
\hline $21^{\circ} 57,12^{\prime}$ & $039^{\circ} 37,32^{\prime}$ & $18 / 06 / 2003$ & vertical & $500-980 m$ & cilíndrico-cônica & 500 & 1 \\
\hline $22^{\circ} 06^{\prime} 37,8^{\prime \prime}$ & $039^{\circ} 49^{\prime} 44,8^{\prime \prime}$ & $10 / 05 / 2002$ & oblíquo & até a termoclina & bongô & 500 & 30 \\
\hline
\end{tabular}

Referências: Nafpakititis et al., 1977; Moser \& Ahlstrom, 1996; Castro \& Bonecker, 2006c; Moser \& Watson, 2006; Fahay, 2007; Santos \& Figueiredo, 2008. 


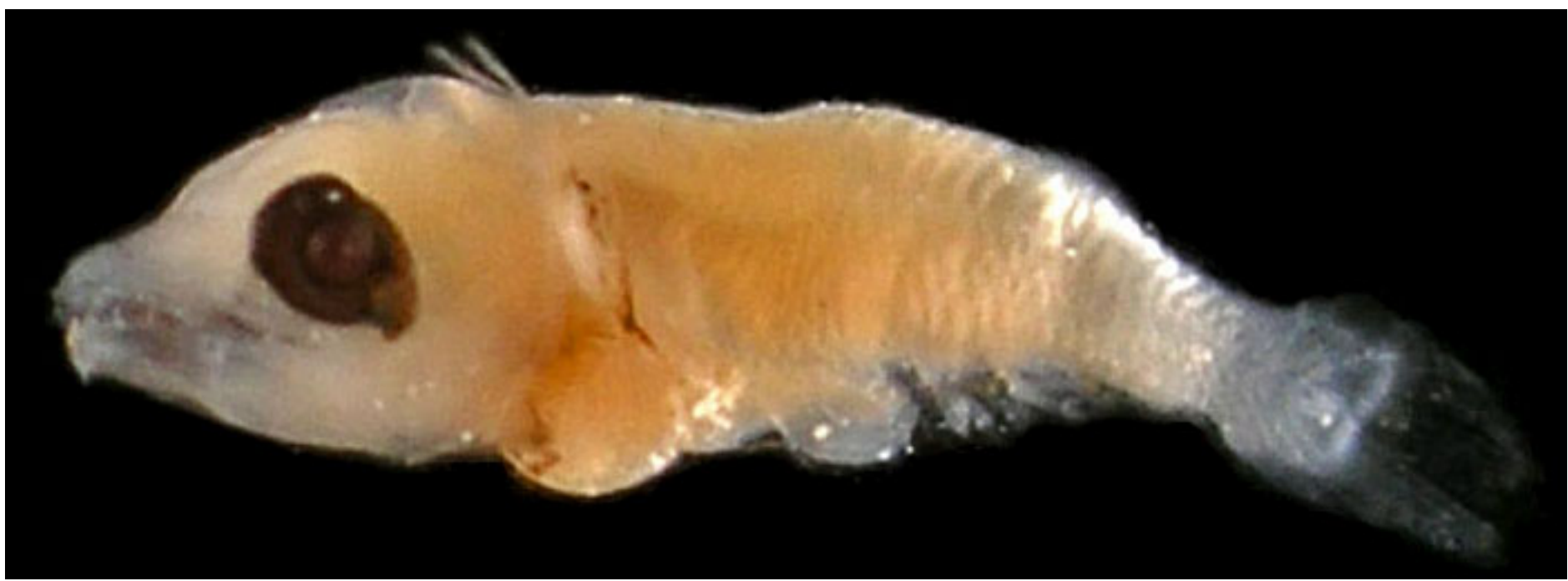

Figura 72 - A: Lobianchia gemellarii. DZUFRJ 22148; Flexão; CP 4,9 mm.

\section{Lobianchia gemellarii (Cocco, 1838)}

Possui cabeça grande e olhos ovais grandes com tecido coroide lunado ventral. A nadadeira peitoral é bilobada com os

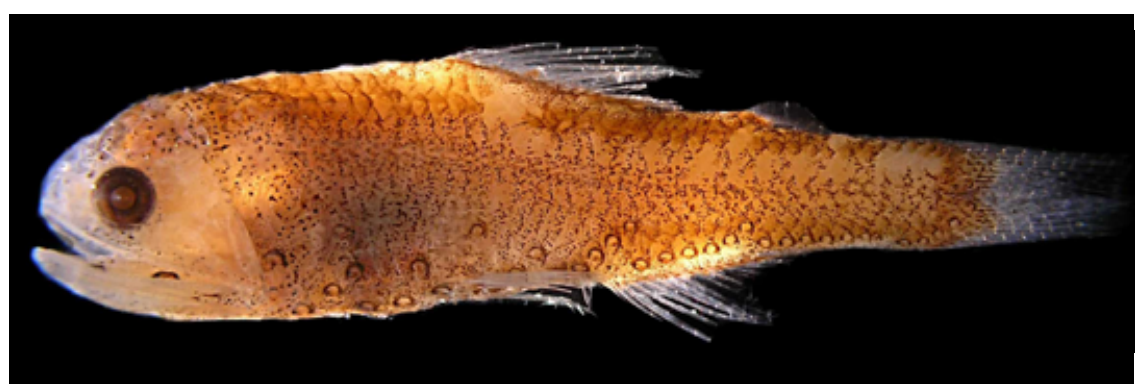

Figura 72 - B: DZUFRJ 22153; Juvenil; CP 25,0 mm. quatro raios superiores precoces mais alongados. Durante a pré-flexão e flexão possui melanóforos na base da nadadeira peitoral, anterior a base da peitoral, na parte anterior do intestino e na região do ânus. Possui pigmentos espalhados nos raios da nadadeira peitoral e pigmentos internos na vesícula gasosa. O número de miômeros varia entre 34 e 35 . Os juvenis possuem 4 Prc, 5 AOa e 6 AOp, SAO normalmente em curva.

Tamanho: flexão 4,9 mm; juvenil 25,0 mm.

Habitat: espécie marinha, epi-mesopelágica, ocorre em águas tropicais e subtropicais entre 325 e $550 \mathrm{~m}$ de profundidade durante o dia. A noite ocorre entre 40 e $175 \mathrm{~m}$ de profundidade.

Nome vulgar: Peixe-lanterna.

\section{Georreferenciamento}

\begin{tabular}{|c|c|c|c|c|c|c|c|c|}
\hline DZUFR & Latitude (S) & Longitude (W) & Data & $\begin{array}{c}\text { Tipo de } \\
\text { arrasto }\end{array}$ & $\begin{array}{c}\text { Profundidade } \\
\text { de coleta }\end{array}$ & Rede & $\begin{array}{c}\text { Malha } \\
\text { ( } \boldsymbol{\mu m} \text { ) }\end{array}$ & $\begin{array}{c}\mathbf{N}^{\circ} \text {. de } \\
\text { inds. }\end{array}$ \\
\hline 22148 & $22^{\circ} 07^{\prime} 29,0^{\prime \prime}$ & $039^{\circ} 06^{\prime} 23,5^{\prime \prime}$ & $10 / 05 / 2002$ & oblíquo & $1.000 \mathrm{~m}$ & cilíndrico-cônica & 500 & 1 \\
\hline 22153 & $21^{\circ} 53^{\prime} 10,4^{\prime \prime}$ & $039^{\circ} 45^{\prime} 49,9^{\prime \prime}$ & $10 / 10 / 2001$ & oblíquo & $1.000 \mathrm{~m}$ & cilíndrico-cônica & 500 & 1 \\
\hline
\end{tabular}

Referências: Nafpakititis et al., 1977; Moser \& Ahlstrom, 1996; Castro \& Bonecker, 2006c; Moser \& Watson, 2006; Fahay, 2007; Santos \& Figueiredo, 2008. 


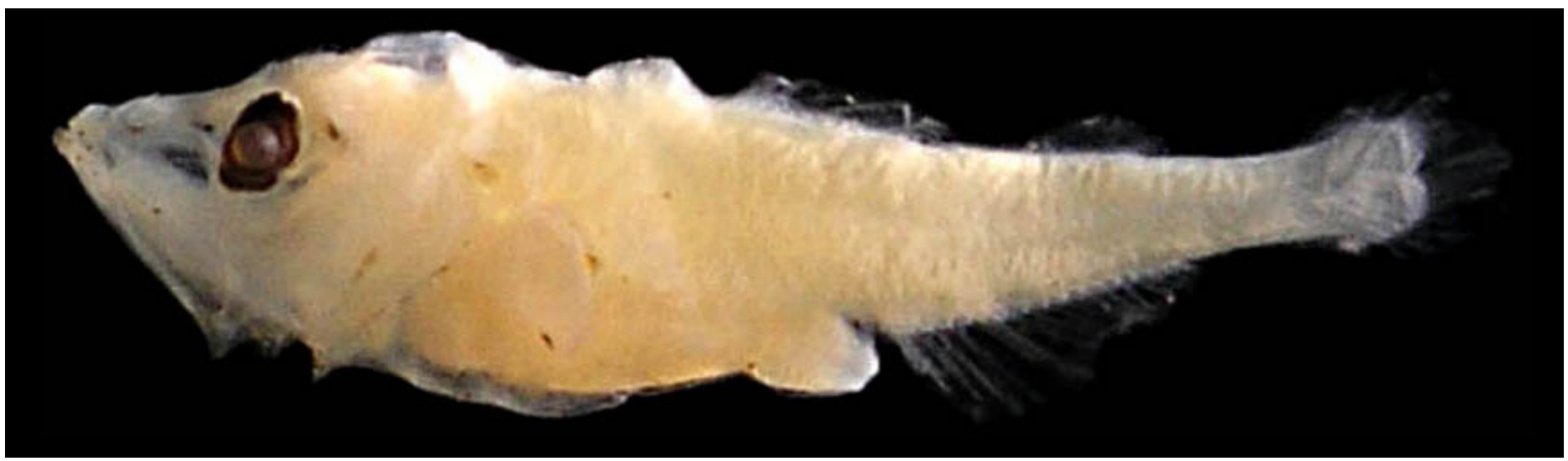

Figura 73- A: Myctophum affine. DZUFRJ 22157; Pós-flexão; CP 7,3 mm.

\section{Myctophum affine (Lütken, 1892)}

As larvas em pré-flexão, flexão e pós-flexão possuem olhos elípticos com uma pequena massa cônica ventral de tecido coroide. As nadadeiras peitorais são grandes e os raios se desenvolvem precocemente. No estágio de flexão há pigmentos nas maxilas, no cleitro, no istmo, um dorsal e um ventral na região posterior do corpo e na superfície ventral do intestino. Possui um ou dois melanóforos na parte interna da base da nadadeira peitoral, enquanto em $M$. nitidulum há vários melanóforos grandes. Na parte dorsal da cabeça existem quatro pigmentos formando um arco e mais um no centro. O número de miômeros varia entre 37 e 38 . Os indivíduos em transformação possuem SAO em linha reta com o VO3; 1 Pol; 2 Prc; 8 a 9 (7) AOa e 5 (4 a 6) AOp; AOp1 normalmente sobre o final da base da nadadeira anal. A margem póstero-dorsal do opérculo é arredondada e nos juvenis, as escamas são ctenóides.

Tamanho: pós-flexão 7,3 mm; juvenil 13,5-21,0 mm; adulto 25,5-49,5 mm.

Habitat: espécie marinha, epi-mesopelágica, ocorre em águas tropicais entre 300 e 650 m de profundidade durante o dia. A noite ocorre desde próximo à superfície até $275 \mathrm{~m}$ de profundidade.

Nome vulgar: Peixe-lanterna.

\section{Georreferenciamento}

\begin{tabular}{|c|c|c|c|c|c|c|c|c|}
\hline DZUFRJ & Latitude (S) & Longitude (W) & Data & $\begin{array}{c}\text { Tipo de } \\
\text { arrasto }\end{array}$ & $\begin{array}{c}\text { Profundidade } \\
\text { de coleta }\end{array}$ & Rede & $\begin{array}{c}\text { Malha } \\
\text { ( } \boldsymbol{\mu m} \text { ) }\end{array}$ & $\begin{array}{c}\mathbf{N}^{\circ} \text {. de } \\
\text { inds. }\end{array}$ \\
\hline 2615 & $22^{\circ} 08^{\prime} 01,8^{\prime \prime}$ & $039^{\circ} 37^{\prime} 30,8^{\prime \prime}$ & $03 / 12 / 2002$ & horizontal & superfície & nêuston & 500 & 10 \\
\hline 2617 & $22^{\circ} 35^{\prime} 08,5^{\prime \prime}$ & $039^{\circ} 46^{\prime} 22,3^{\prime \prime}$ & $07 / 12 / 2002$ & horizontal & superfície & nêuston & 500 & 4 \\
\hline 2620 & $22^{\circ} 35^{\prime} 08,5^{\prime \prime}$ & $039^{\circ} 46^{\prime} 22,3^{\prime \prime}$ & $07 / 12 / 2002$ & horizontal & superfície & nêuston & 500 & 2 \\
\hline 5554 & $22^{\circ} 32^{\prime} 49,0^{\prime \prime}$ & $040^{\circ} 04^{\prime} 20,9^{\prime \prime}$ & $07 / 11 / 2001$ & oblíquo & $1.000 \mathrm{~m}$ & cilíndrico-cônica & 500 & 1 \\
\hline 5556 & $22^{\circ} 32^{\prime} 49,0^{\prime \prime}$ & $040^{\circ} 04^{\prime} 20,9^{\prime \prime}$ & $07 / 11 / 2001$ & oblíquo & $1.000 \mathrm{~m}$ & cilíndrico-cônica & 500 & 1 \\
\hline 22018 & $22^{\circ} 08^{\prime} 14,9^{\prime \prime}$ & $039^{\circ} 46^{\prime} 34,6^{\prime \prime}$ & $11 / 05 / 2002$ & oblíquo & até a termoclina & bongô & 330 & 2 \\
\hline
\end{tabular}




\begin{tabular}{|c|c|c|c|c|c|c|c|c|}
\hline DZUFRJ & Latitude (S) & Longitude (W) & Data & $\begin{array}{l}\text { Tipo de } \\
\text { arrasto }\end{array}$ & $\begin{array}{l}\text { Profundidade } \\
\text { de coleta }\end{array}$ & Rede & $\begin{array}{l}\text { Malha } \\
(\mu \mathrm{m})\end{array}$ & $\begin{array}{l}N^{\circ} \text {. de } \\
\text { inds. }\end{array}$ \\
\hline 23130 & $22^{\circ} 08,03^{\prime}$ & $039^{\circ} 50,11^{\prime}$ & $16 / 06 / 2003$ & horizontal & superfície & nêuston & 500 & 7 \\
\hline 23131 & $22^{\circ} 08,07^{\prime}$ & $039^{\circ} 37,58^{\prime}$ & $17 / 06 / 2003$ & horizontal & superfície & nêuston & 500 & 2 \\
\hline 23135 & $21^{\circ} 57^{\prime} 08,3^{\prime \prime}$ & $039^{\circ} 49^{\prime} 05,2^{\prime \prime}$ & 05/12/2002 & horizontal & superfície & nêuston & 500 & 18 \\
\hline 23136 & $21^{\circ} 57^{\prime} 08,3^{\prime \prime}$ & $039^{\circ} 49^{\prime} 05,2^{\prime \prime}$ & $05 / 12 / 2002$ & horizontal & superfície & nêuston & 500 & 5 \\
\hline 23137 & $22^{\circ} 02^{\prime} 35,2^{\prime \prime}$ & $039^{\circ} 43^{\prime} 18,2^{\prime \prime}$ & $04 / 12 / 2002$ & horizontal & superfície & nêuston & 500 & 6 \\
\hline 23795 & $22^{\circ} 02^{\prime} 35,2^{\prime \prime}$ & $039^{\circ} 43^{\prime} 18,2^{\prime \prime}$ & 04/12/2002 & horizontal & superfície & nêuston & 500 & 1 \\
\hline 23796 & $22^{\circ} 08,03^{\prime}$ & $039^{\circ} 50,11^{\prime}$ & $16 / 06 / 2003$ & horizontal & superfície & nêuston & 500 & 8 \\
\hline 23832 & $22^{\circ} 02,27^{\prime}$ & $039^{\circ} 43,49^{\prime}$ & $18 / 06 / 2003$ & horizontal & superfície & nêuston & 500 & 1 \\
\hline 23881 & $22^{\circ} 43^{\prime} 50,4^{\prime \prime}$ & $039^{\circ} 53^{\prime} 20,5^{\prime \prime}$ & $07 / 12 / 2002$ & horizontal & superfície & nêuston & 500 & 10 \\
\hline 23892 & $22^{\circ} 43^{\prime} 50,4^{\prime \prime}$ & $039^{\circ} 53^{\prime} 20,5^{\prime \prime}$ & $07 / 12 / 2002$ & horizontal & superfície & nêuston & 500 & 4 \\
\hline
\end{tabular}

Referências: Nafpakititis et al., 1977; Moser \& Ahlstrom, 1996; Castro \& Bonecker, 2006c; Moser \& Watson, 2006; Fahay, 2007; Santos \& Figueiredo, 2008. 


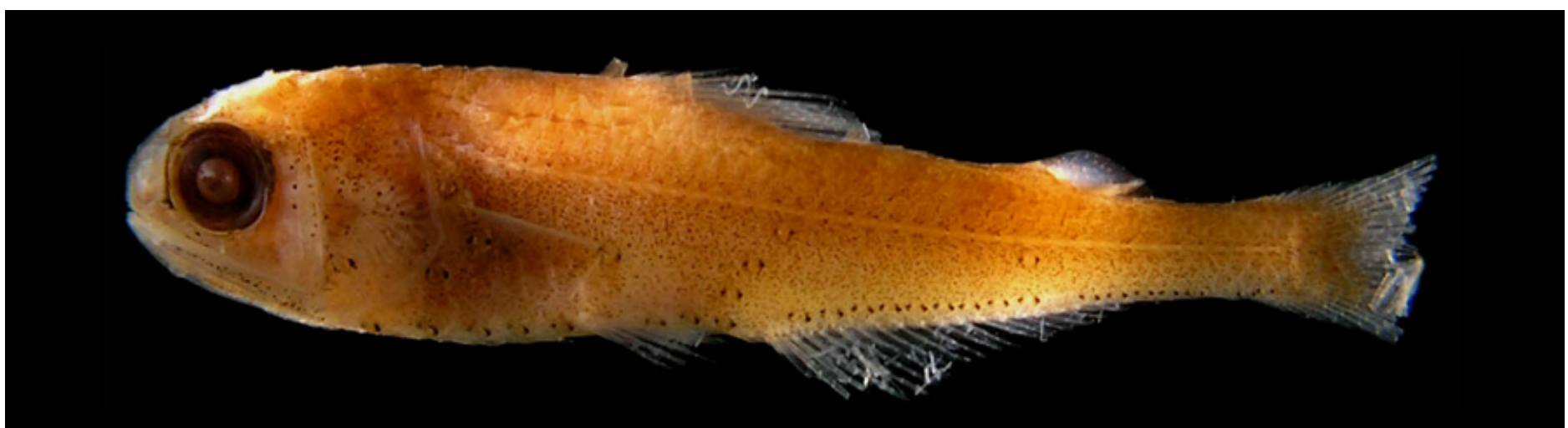

Figura 74 - A: Myctophum nitidulum. DZUFRJ 22159; Juvenil; CP 26,5 mm.

\section{Myctophum nitidulum Garman, 1899}

As larvas em pré-flexão, flexão e pós-flexão possuem olhos elípticos com uma pequena massa cônica ventral de tecido coroide. As nadadeiras peitorais são grandes e os raios se desenvolvem precocemente. No estágio de

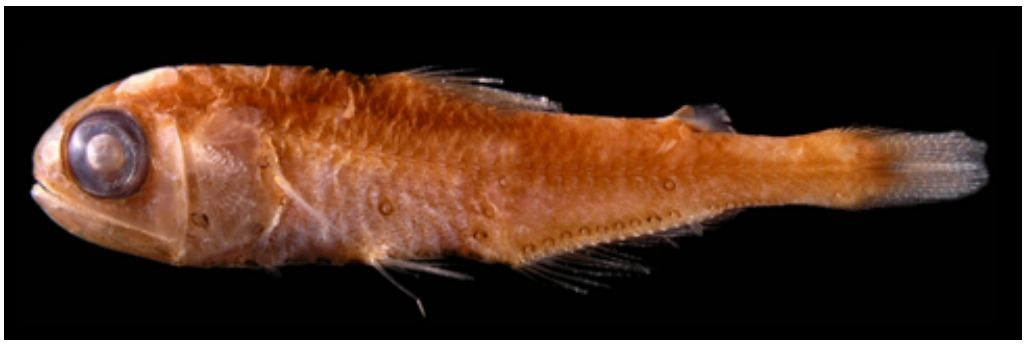

Figura 74 - B: DZUFRJ 22144; Adulto; CP 37,0 mm.

flexão há pigmentos na extremidade da maxila inferior, dois na margem dorsal e um na margem ventral do corpo, um no focinho e outros na região ventral do intestino, no opérculo e na base da nadadeira peitoral. Possui vários melanóforos grandes na parte interna da base da nadadeira peitoral, enquanto em $M$. affine há um ou dois melanóforos. Olhando a cabeça dorsalmente pode-se observar um par de pigmentos na parte lateral posterior do cérebro. O número de miômeros varia entre 36 e 39. Os indivíduos em transformação apresentam SAO em linha reta passando atrás do VO3; 2 Prc; Pol acima do último AOa; 9 (8 a 10) AOa e 5 (4 a 6) AOp; AOp1 normalmente sobre o final da base da nadadeira anal. A margem póstero-dorsal do opérculo é angular e pontuda; nos indivíduos em transformação ou juvenis, as escamas são cicloides.

Tamanho: pós-flexão 7,3 mm; juvenil 26,5 mm; adulto 37,0 mm.

Habitat: espécie marinha, epi-mesopelágica, ocorre em águas tropicais entre 475 e $850 \mathrm{~m}$ de profundidade durante o dia. A noite ocorre próximo à superfície.

Nome vulgar: Peixe-lanterna.

\section{Georreferencimento}

\begin{tabular}{|c|c|c|c|c|c|c|c|c|}
\hline DZUFR & Latitude & Longitude & Data & $\begin{array}{c}\text { Tipo de } \\
\text { arrasto }\end{array}$ & $\begin{array}{c}\text { Profundidade } \\
\text { de coleta }\end{array}$ & Rede & $\begin{array}{c}\text { Malha } \\
\text { ( } \begin{array}{c}\boldsymbol{\mu} \text { m) } \\
\text { inds. }\end{array}\end{array}$ & $\begin{array}{c}\text { No. de } \\
\text { inds. }\end{array}$ \\
\hline 22144 & $21^{\circ} 54^{\prime} 36,5^{\prime \prime}$ & $039^{\circ} 45^{\prime} 20,0^{\prime \prime}$ & $09 / 10 / 2001$ & oblíquo & $1.000 \mathrm{~m}$ & cilíndrico-cônica & 500 & 1 \\
\hline 22157 & $22^{\circ} 33^{\prime} 47,7^{\prime \prime}$ & $040^{\circ} 12^{\prime} 20,5^{\prime \prime}$ & $17 / 05 / 2002$ & oblíquo & $50 \mathrm{~m}$ & bongô & 500 & 1 \\
\hline 22159 & $22^{\circ} 31^{\prime} 40,9^{\prime \prime}$ & $040^{\circ} 02^{\prime} 39,6^{\prime \prime}$ & $07 / 11 / 2001$ & oblíquo & $1.000 \mathrm{~m}$ & cilíndrico-cônica & 500 & 1 \\
\hline
\end{tabular}

Referências: Nafpakititis et al., 1977; Moser \& Ahlstrom, 1996; Castro \& Bonecker, 2006c; Moser \& Watson, 2006; Fahay, 2007; Santos \& Figueiredo, 2008. 


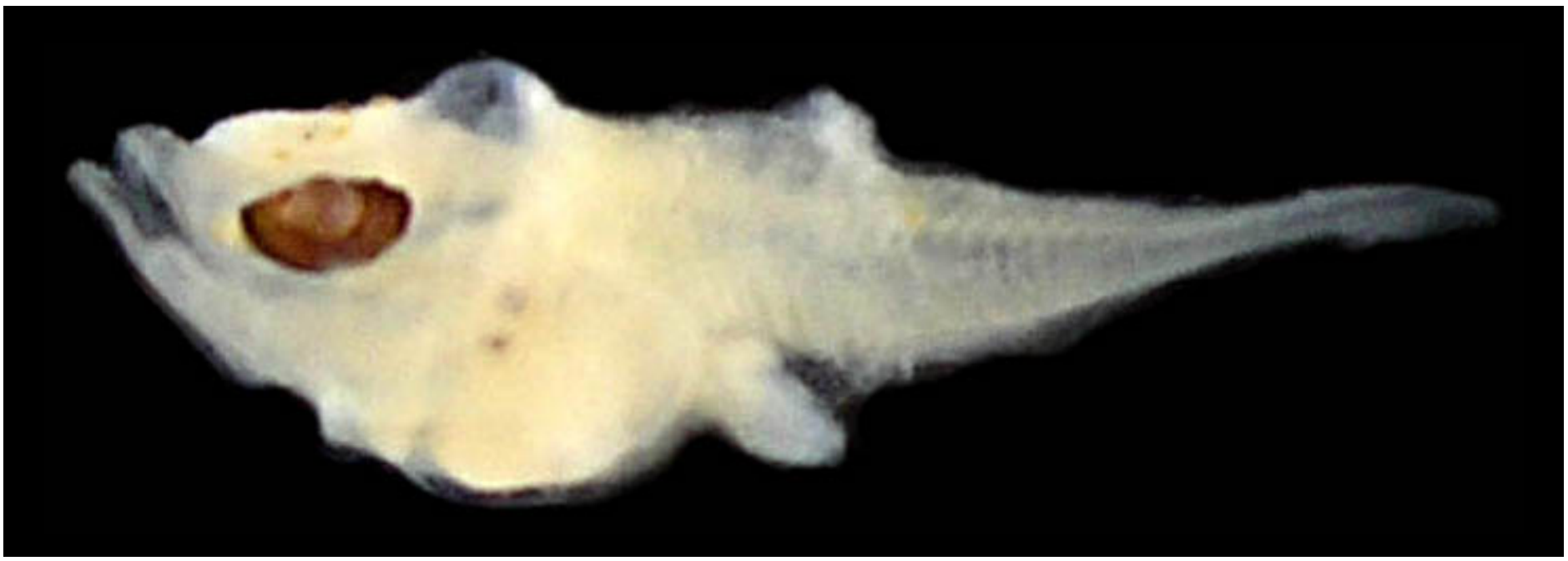

Figura 75- A: Myctophum obtusirostre. DZUFRJ 22174; Pré-flexão; CP 3,4 mm.

\section{Myctophum obtusirostre Tåning, 1928}

Na pré-flexão, flexão e pós-flexão possui o corpo alto, mandíbula grande e olhos ovais com uma pequena massa cônica ventral de tecido coroide. As larvas no estágio de flexão possuem pigmentos nas extremidades das maxilas, na região anterior do cérebro, na base da nadadeira peitoral, no intestino e no cleitro. A distância pré-anal aumenta da pré-flexão $(<50 \%)$ para a pós-flexão (>60\%). O número de miômeros varia entre 35 e 36. Os indivíduos em transformação apresentam PLO anterior à base da nadadeira peitoral, SAO um pouco curvo, SAO1 um pouco a frente do VO4; 1 Pol sobre o último AOa; 2 Prc; 7 (6 a 8) AOa e 4 (3 a 5) AOp; AOp1 normalmente sobre a base da nadadeira anal. Nos indivíduos em trans-

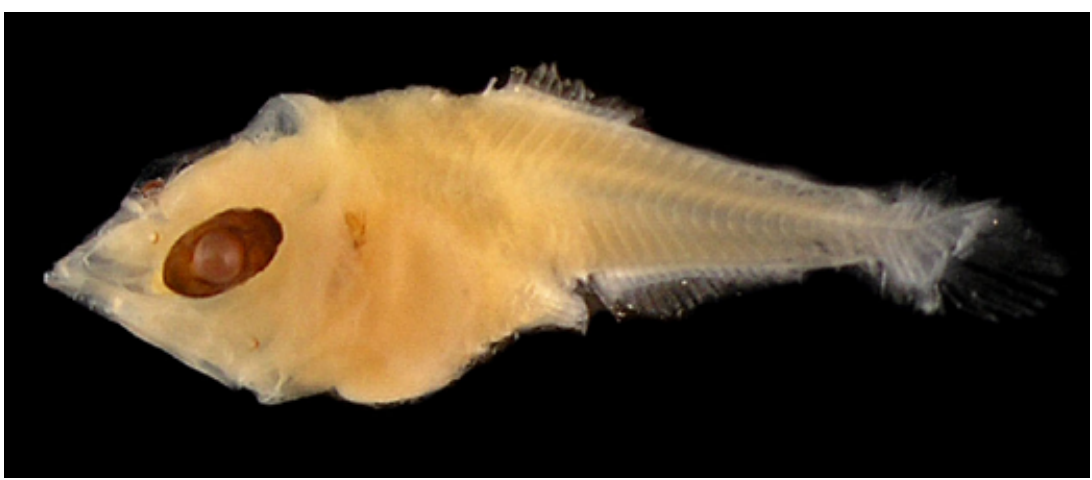

Figura 75- B: DZUFRJ 5511; Flexão; CP 5,5 mm.

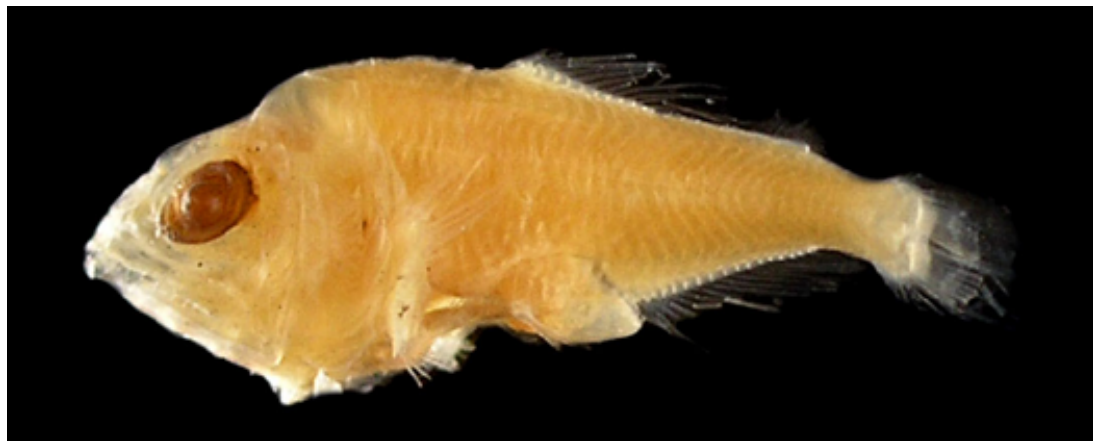

Figura 75 - C: DZUFRJ 10945; Pós-flexão; CP 7,0 mm. formação e juvenis, as escamas são cicloides.

Tamanho: pré-flexão 3,0-3,9 mm; flexão 4,0-5,9 mm; pós-flexão 6,0-7,4 mm; juvenil 15,0-17,2 $\mathrm{mm}$.

Habitat: espécie marinha, epi-mesopelágica, ocorre em águas tropicais entre 325 e $750 \mathrm{~m}$ de profundidade durante o dia. A noite ocorre próximo à superfície.

Nome vulgar: Peixe-lanterna. 


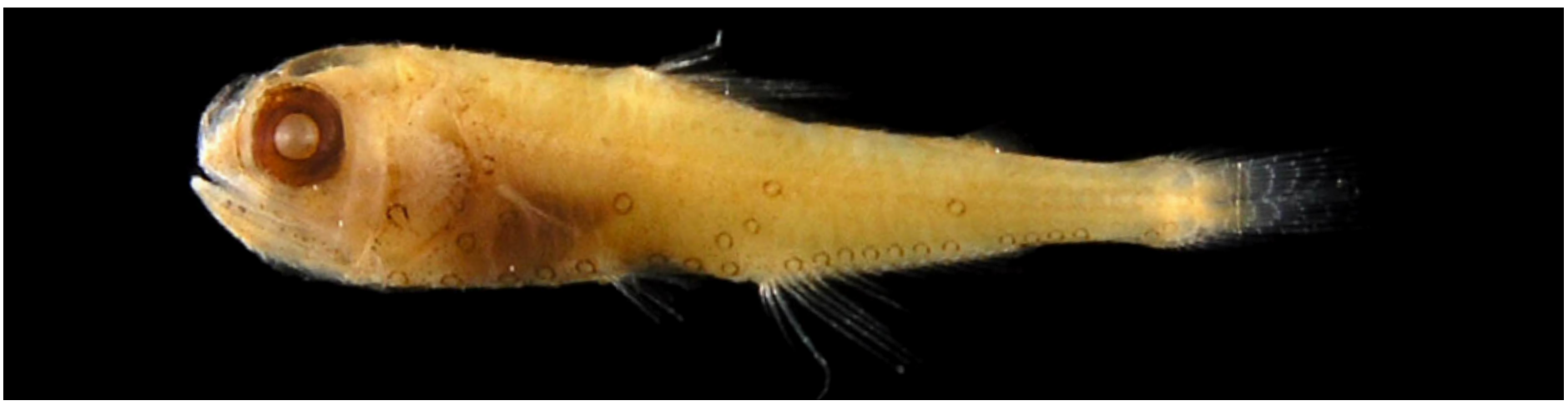

Figura 75 - D: DZUFRJ 22154; Juvenil; CP 17,0 mm.

\section{Georreferencimento}

\begin{tabular}{|c|c|c|c|c|c|c|c|c|}
\hline DZUFRJ & Latitude (S) & Longitude (W) & Data & $\begin{array}{l}\text { Tipo de } \\
\text { arrasto }\end{array}$ & $\begin{array}{l}\text { Profundidade } \\
\text { de coleta }\end{array}$ & Rede & $\begin{array}{c}\text { Malha } \\
(\mu \mathrm{m})\end{array}$ & $\begin{array}{l}N^{\circ} \text {. de } \\
\text { inds. }\end{array}$ \\
\hline 5511 & $22^{\circ} 32^{\prime} 50,0^{\prime \prime}$ & $040^{\circ} 04^{\prime} 09,9 "$ & $06 / 11 / 2001$ & oblíquo & $1.000 \mathrm{~m}$ & cilíndrico-cônica & 500 & 2 \\
\hline 7533 & $22^{\circ} 32^{\prime} 50,0^{\prime \prime}$ & $040^{\circ} 04^{\prime} 09,9^{\prime \prime}$ & 06/11/2001 & oblíquo & $1.000 \mathrm{~m}$ & cilíndrico-cônica & 500 & 1 \\
\hline 7556 & $21^{\circ} 54^{\prime} 36,5^{\prime \prime}$ & $039^{\circ} 45^{\prime} 20,0^{\prime \prime}$ & $10 / 10 / 2001$ & oblíquo & $1.000 \mathrm{~m}$ & cilíndrico-cônica & 500 & 1 \\
\hline 7569 & $21^{\circ} 53^{\prime} 10,4^{\prime \prime}$ & $039^{\circ} 45^{\prime} 49,9^{\prime \prime}$ & $10 / 10 / 2001$ & oblíquo & $1.000 \mathrm{~m}$ & cilíndrico-cônica & 500 & 1 \\
\hline 7572 & $21^{\circ} 54^{\prime} 36,5^{\prime \prime}$ & $039^{\circ} 45^{\prime} 20,0^{\prime \prime}$ & 09/10/2001 & oblíquo & $1.000 \mathrm{~m}$ & cilíndrico-cônica & 500 & 3 \\
\hline 21989 & $21^{\circ} 54^{\prime} 36,5^{\prime \prime}$ & $039^{\circ} 45^{\prime} 20,0^{\prime \prime}$ & $10 / 10 / 2001$ & oblíquo & $0 \mathrm{~m}$ & cilíndrico-cônica & 500 & 2 \\
\hline 21990 & $21^{\circ} 57^{\prime} 10,5^{\prime \prime}$ & $039^{\circ} 43^{\prime} 33,3^{\prime \prime}$ & 09/10/2001 & oblíquo & $1.000 \mathrm{~m}$ & cilíndrico-cônica & 500 & 3 \\
\hline 21992 & $21^{\circ} 58^{\prime} 31,0^{\prime \prime}$ & $039^{\circ} 50^{\prime} 29,7^{\prime \prime}$ & $11 / 10 / 2001$ & oblíquo & $1.000 \mathrm{~m}$ & cilíndrico-cônica & 500 & 3 \\
\hline 22013 & $21^{\circ} 58^{\prime} 31,0^{\prime \prime}$ & $039^{\circ} 50^{\prime} 29,7^{\prime \prime}$ & $10 / 10 / 2001$ & oblíquo & & cilíndrico-cônica & 500 & 2 \\
\hline 22024 & $21^{\circ} 53^{\prime} 10,4^{\prime \prime}$ & $039^{\circ} 45^{\prime} 49,9^{\prime \prime}$ & $10 / 10 / 2001$ & oblíquo & $1.000 \mathrm{~m}$ & cilíndrico-cônica & 500 & 1 \\
\hline 22040 & $22^{\circ} 03^{\prime} 03,3^{\prime \prime}$ & $039^{\circ} 50^{\prime} 39,0^{\prime \prime}$ & $10 / 05 / 2002$ & oblíquo & até a termoclina & bongô & 330 & 1 \\
\hline 22044 & $22^{\circ} 02^{\prime} 30,0^{\prime \prime}$ & $039^{\circ} 49^{\prime} 41,2^{\prime \prime}$ & $12 / 05 / 2002$ & oblíquo & & cilíndrico-cônica & 500 & 1 \\
\hline 22089 & $22^{\circ} 32^{\prime} 50,0^{\prime \prime}$ & $040^{\circ} 04^{\prime} 09,9^{\prime \prime}$ & $06 / 11 / 2001$ & oblíquo & $1.000 \mathrm{~m}$ & cilíndrico-cônica & 500 & 1 \\
\hline 22090 & $22^{\circ} 31^{\prime} 58,9^{\prime \prime}$ & $040^{\circ} 02^{\prime} 53,4^{\prime \prime}$ & $07 / 11 / 2001$ & oblíquo & $1.000 \mathrm{~m}$ & cilíndrico-cônica & 500 & 1 \\
\hline 22151 & $22^{\circ} 08^{\prime} 17,5^{\prime \prime}$ & $039^{\circ} 46^{\prime} 28,5^{\prime \prime}$ & $11 / 05 / 2002$ & oblíquo & $1.000 \mathrm{~m}$ & cilíndrico-cônica & 500 & 3 \\
\hline 22154 & $21^{\circ} 57^{\prime} 08,3^{\prime \prime}$ & $039^{\circ} 49^{\prime} 05,2^{\prime \prime}$ & $05 / 12 / 2002$ & horizontal & superfície & nêuston & 500 & 2 \\
\hline 22171 & $22^{\circ} 08^{\prime} 14,9^{\prime \prime}$ & $039^{\circ} 46^{\prime} 34,6^{\prime \prime}$ & $11 / 05 / 2002$ & oblíquo & até a termoclina & bongô & 500 & 1 \\
\hline 22174 & $22^{\circ} 33^{\prime} 47,7^{\prime \prime}$ & $040^{\circ} 12^{\prime} 20,5^{\prime \prime}$ & $17 / 05 / 2002$ & oblíquo & $50 \mathrm{~m}$ & bongô & 500 & 1 \\
\hline 23129 & $21^{\circ} 57^{\prime} 08,3^{\prime \prime}$ & $039^{\circ} 49^{\prime} 05,2^{\prime \prime}$ & $05 / 12 / 2002$ & horizontal & superfície & nêuston & 500 & 2 \\
\hline
\end{tabular}

Referências: Nafpakititis et al., 1977; Moser \& Ahlstrom, 1996; Castro \& Bonecker, 2006c; Moser \& Watson, 2006; Fahay, 2007; Santos \& Figueiredo, 2008. 


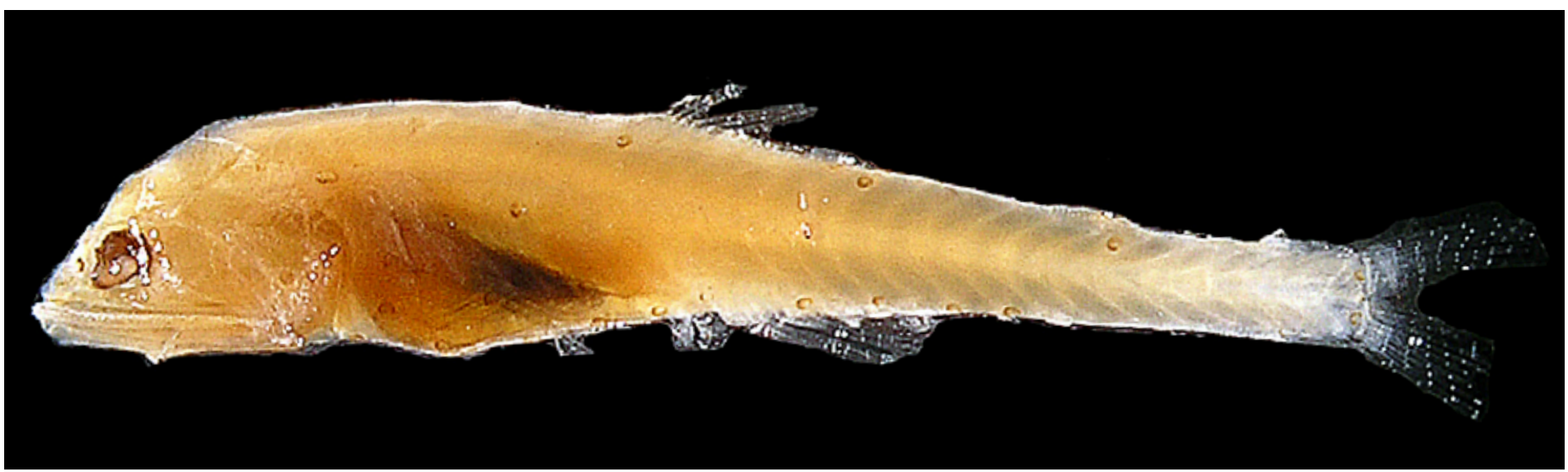

Figura 76 - A: Notolychnus valdiviae. DZUFRJ 1210; Transformação; CP 14,7 mm.

\section{Notolychnus valdiviae (Brauer, 1904)}

A principal característica dos indivíduos em transformação e dos juvenis é a posição dos fotóforos VLO, SAO3 e

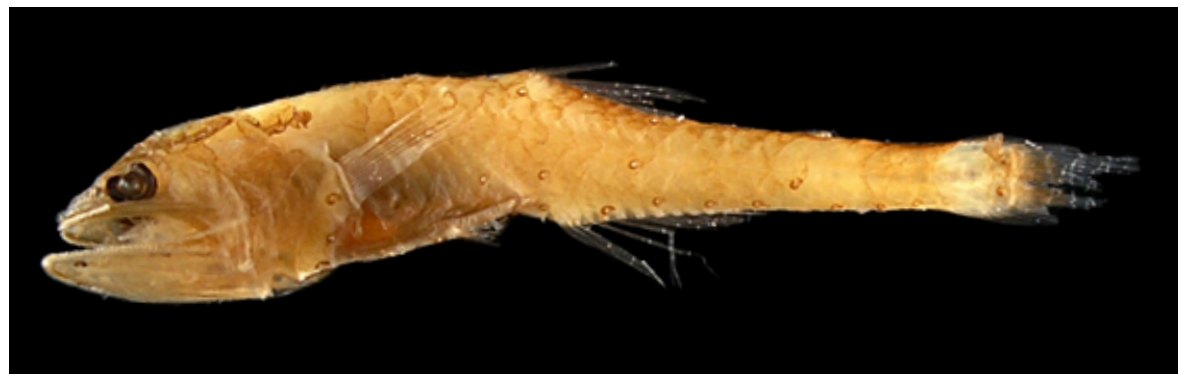

Figura 76 - B: DZUFRJ 22146; Juvenil; CP 19,2 mm. Pol2 que estão situados bem próximo à margem dorsal do corpo. Além disso, possuem um Dn pequeno; PLO bem à frente da base da nadadeira peitoral quase em contato com ela. Os fotóforos PO1, PO2 e PO5 são equidistantes formando uma linha horizontal; PO3 elevado até o nível do PVO1; PO4 muito elevado. O VO1 é elevado à frente do VO2; SAO um pouco angular, SAO3 muito próximo ao final da nadadeira dorsal; 2 Pol, Pol2 próximo à base da nadadeira adiposa; 2 Prc, o segundo situado acima do primeiro; $4 \mathrm{AOa}$ e 4 (3) AOp. O número de miômeros varia entre 27 e 31.

Tamanho: transformação 11,0-15,0 mm; juvenil 17,2-19,2 mm.

Habitat: espécie marinha, epi-mesopelágica, ocorre em águas tropicais e temperadas entre 375 e $650 \mathrm{~m}$ de profundidade durante o dia. A noite ocorre entre 40 e $125 \mathrm{~m}$ de profundidade.

Nome vulgar: Peixe-lanterna.

\section{Georreferencimento}

\begin{tabular}{|c|c|c|c|c|c|c|c|c|}
\hline DZUFR & Latitude (S) & Longitude (W) & Data & $\begin{array}{c}\text { Tipo de } \\
\text { arrasto }\end{array}$ & $\begin{array}{c}\text { Profundidade } \\
\text { de coleta }\end{array}$ & Rede & $\begin{array}{c}\text { Malha } \\
(\boldsymbol{\mu m})\end{array}$ & $\begin{array}{c}\mathbf{N}^{\circ} \text {. de } \\
\text { inds. }\end{array}$ \\
\hline 1200 & $22^{\circ} 06^{\prime} 52,3^{\prime \prime}$ & $039^{\circ} 48^{\prime} 46,2^{\prime \prime}$ & $11 / 05 / 2002$ & oblíquo & $1.000 \mathrm{~m}$ & cilíndrico-cônica & 500 & 2 \\
\hline 1210 & $22^{\circ} 02^{\prime} 30,0^{\prime \prime}$ & $039^{\circ} 49^{\prime} 41,2^{\prime \prime}$ & $12 / 05 / 2002$ & oblíquo & $1.000 \mathrm{~m}$ & cilíndrico-cônica & 500 & 3 \\
\hline 22021 & $2^{\circ} 54^{\prime} 36,5^{\prime \prime}$ & $039^{\circ} 45^{\prime} 20,0^{\prime \prime}$ & $10 / 10 / 2001$ & oblíquo & $1.000 \mathrm{~m}$ & cilíndrico-cônica & 500 & 2 \\
\hline 22025 & $21^{\circ} 58^{\prime} 31,0^{\prime \prime}$ & $039^{\circ} 50^{\prime} 29,7^{\prime \prime}$ & $10 / 10 / 2001$ & oblíquo & $1.000 \mathrm{~m}$ & cilíndrico-cônica & 500 & 2 \\
\hline 22146 & $22^{\circ} 32^{\prime} 49,0^{\prime \prime}$ & $040^{\circ} 04^{\prime} 20,9^{\prime \prime}$ & $07 / 11 / 2001$ & oblíquo & $1.000 \mathrm{~m}$ & cilíndrico-cônica & 500 & 1 \\
\hline
\end{tabular}

Referências: Nafpakititis et al., 1977; Castro \& Bonecker, 2006c; Fahay, 2007; Santos \& Figueiredo, 2008. 


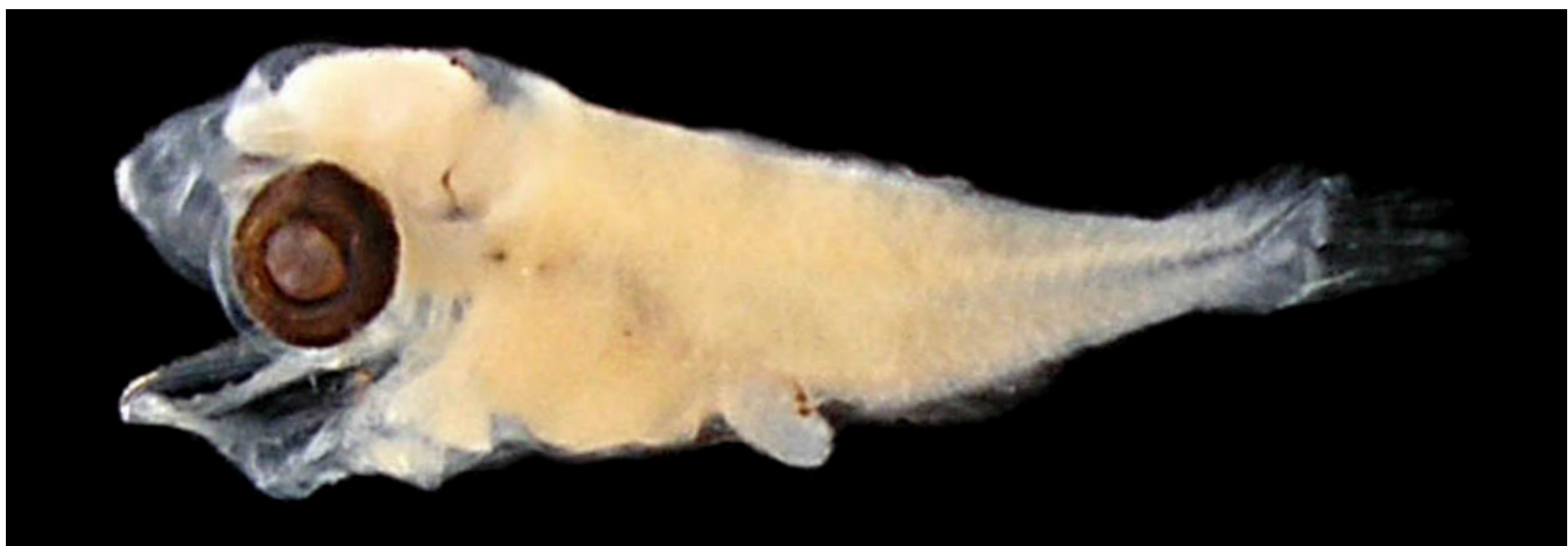

Figura 77: Notoscopelus caudispinosus. DZUFRJ 22172; Flexão; CP 5,1mm.

\section{Notoscopelus caudispinosus (Johnson, 1863)}

Possui cabeça e olhos grandes. Os dentes curvos se formam na maxila inferior no estágio de pré-flexão e o focinho é arredondado durante a flexão. O intestino é muito curto nos estágios iniciais (43\% CP), aumentando em larvas maiores (66\% CP). Possui 37 miômeros. Tem pigmentos no intestino e na cabeça na região posterior do olho. Larvas maiores (5,6 CP) tem dois melanóforos proeminentes no topo da cabeça.

Tamanho: flexão 5,1 mm.

Habitat: Espécie marinha, epi-mesopelágica, ocorre em águas tropicais e subtropicais entre 600 e $1.150 \mathrm{~m}$ de profundidade durante o dia. A noite ocorre entre 20 e $100 \mathrm{~m}$ de profundidade.

Nome vulgar: Peixe-lanterna.

Georreferencimento

\begin{tabular}{|c|c|c|c|c|c|c|c|c|}
\hline DZUFRJ & Latitude (S) & Longitude (W) & Data & $\begin{array}{c}\text { Tipo de } \\
\text { arrasto }\end{array}$ & $\begin{array}{c}\text { Profundidade } \\
\text { de coleta }\end{array}$ & Rede & $\begin{array}{c}\text { Malha } \\
(\boldsymbol{\mu m})\end{array}$ & $\begin{array}{c}\mathbf{N}^{\circ} \text {. de } \\
\text { inds. }\end{array}$ \\
\hline 22172 & $21^{\circ} 54^{\prime} 36,5^{\prime \prime}$ & $039^{\circ} 45^{\prime} 20,0^{\prime \prime}$ & $09 / 10 / 2001$ & oblíquo & $1.000 \mathrm{~m}$ & cilíndrico-cônica & 500 & 1 \\
\hline
\end{tabular}

Referências: Moser \& Ahlstrom, 1996; Moser \& Watson, 2006; Fahay, 2007. 


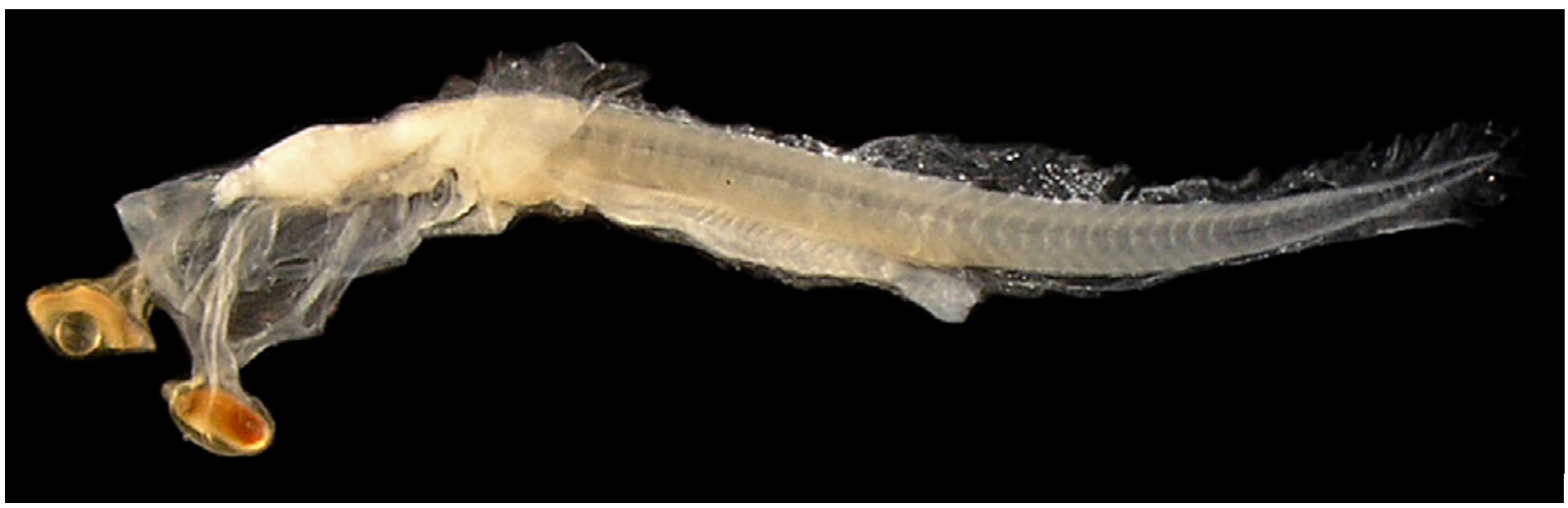

Figura 78 - A: Symbolophorus rufinus. DZUFRJ 13589; Pré-flexão; CP 6,0 mm.

\section{Symbolophorus rufinus Tåning, 1928}

Possui corpo alongado, com 37 miômeros. A cabeça é achatada e os olhos são ovais e muito pedunculados, com tecido coroide pequeno. O intestino é longo e alcança mais da metade do corpo. A

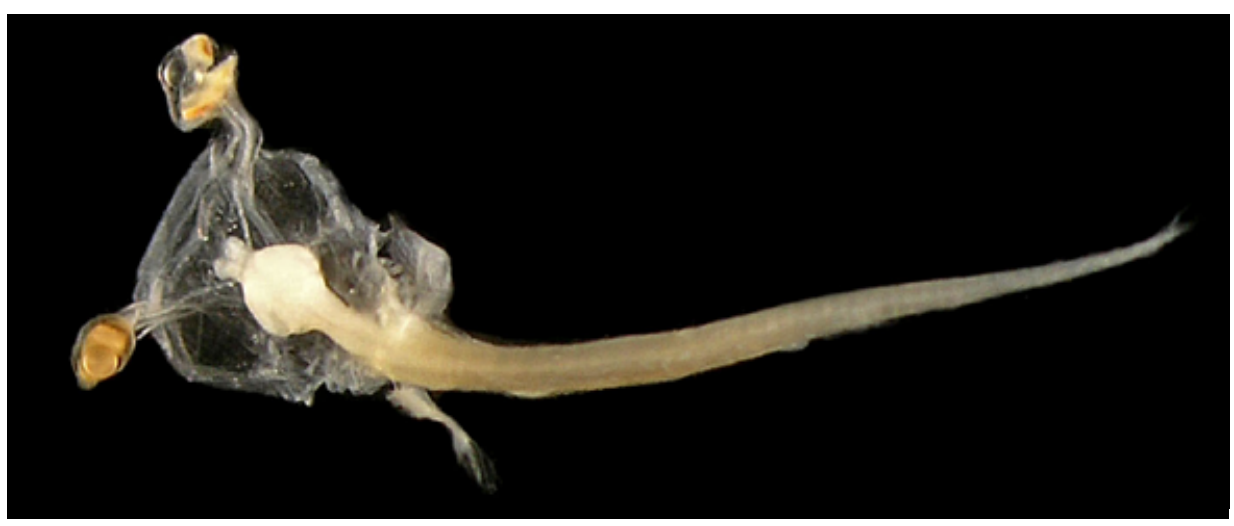

Figura 78 - B: Vista dorsal dos olhos ovais pedunculados. nadadeira peitoral se desenvolve precocemente, é grande e tem forma de asa. Tem pigmentos no istmo, na lateral do intestino, na extremidade da maxila superior e na região posterior da cabeça.

Tamanho: pré-flexão 4,0-6,0 mm.

Habitat: espécie marinha, epi-mesopelágica, ocorre em águas tropicais e subtropicais entre 425 e $850 \mathrm{~m}$ de profundidade durante o dia. A noite ocorre desde próximo à superfície até $125 \mathrm{~m}$ de profundidade.

Nome vulgar: Peixe-lanterna.

\section{Georreferencimento}

\begin{tabular}{|c|c|c|c|c|c|c|c|c|}
\hline DZUFRJ & Latitude (S) & Longitude (W) & Data & $\begin{array}{l}\text { Tipo de } \\
\text { arrasto }\end{array}$ & $\begin{array}{l}\text { Profundidade } \\
\text { de coleta }\end{array}$ & Rede & $\begin{array}{c}\text { Malha } \\
(\mu \mathrm{m})\end{array}$ & $\begin{array}{l}N^{\circ} \text {. de } \\
\text { inds. }\end{array}$ \\
\hline 5551 & $22^{\circ} 31^{\prime} 40,9^{\prime \prime}$ & $040^{\circ} 02 ' 39,6^{\prime \prime}$ & $07 / 11 / 2001$ & oblíquo & $1.000 \mathrm{~m}$ & cilíndrico-cônica & 500 & 1 \\
\hline 22085 & $22^{\circ} 31^{\prime} 40,9^{\prime \prime}$ & $040^{\circ} 02^{\prime} 39,6^{\prime \prime}$ & $07 / 11 / 2001$ & oblíquo & $1.000 \mathrm{~m}$ & cilíndrico-cônica & 500 & 1 \\
\hline 22152 & $21^{\circ} 58^{\prime} 31,0^{\prime \prime}$ & $039^{\circ} 50^{\prime 29,7 "}$ & $10 / 10 / 2001$ & oblíquo & $1.000 \mathrm{~m}$ & cilíndrico-cônica & 500 & 1 \\
\hline
\end{tabular}

Referências: Moser \& Ahlstrom, 1996; Castro \& Bonecker, 2006c; Moser \& Watson, 2006; Fahay, 2007. 